\title{
SÍNTESES TOTAIS DAS CROCACINAS A, C E D: NOVOS ANTIBIÓTICOS ISOLADOS DE Chondromyces crocatus E Chondromyces pediculatus ${ }^{\#}$
}

Luciana G. de Oliveira,* Luiz C. Dias e Giovanni B. Rosso

Instituto de Química, Universidade Estadual de Campinas, CP 6154, 13084-862 Campinas - SP, Brasil

Recebido em 4/10/07; aceito em 18/2/08; publicado na web em 2/4/08

TOTAL SYNTHESIS OF CROCACINS A, C AND D: NEW ANTIBIOTICS ISOLATED FROM Chondromyces crocatus AND Chondromyces pediculatus. This review describes the endeavors that led to the total synthesis of a novel class of antibiotic compounds: the crocacins A-D. Other aspects such as isolation, structural elucidation as well as the biological activities are also presented.

Keywords: crocacins A-D; novel antibiotics; enantioselective total synthesis.

\section{INTRODUÇÃO}

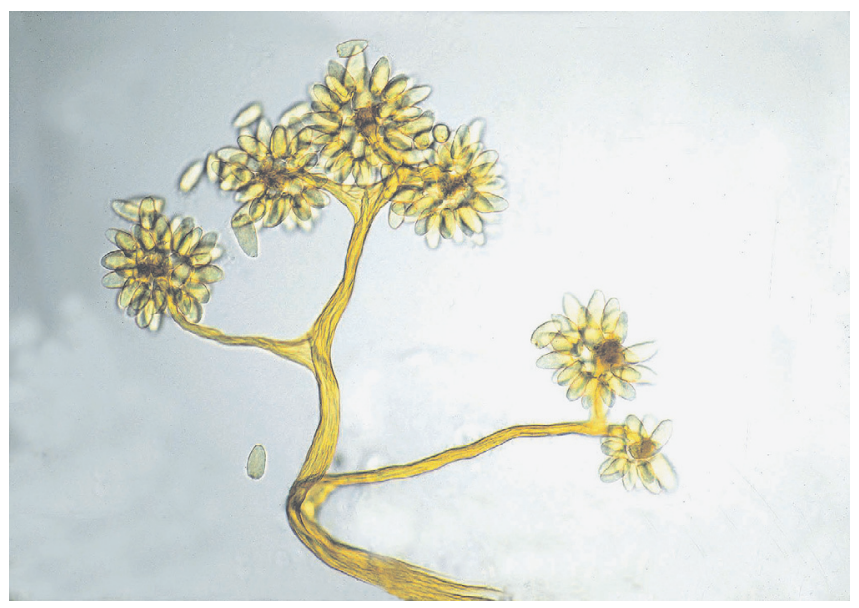

Figura 1. Chondromyces crocatus: A bactéria que queria ser fungo! (Reproduzida da URL com permissão do Prof. George L. Barron (University of Guelph, Guelph, Canadá): http://www.uoguelph.ca/ gbarron/ MISCELLANEOUS/nov00.htm)

As crocacinas A (1), B (2), C (3) e D (4), Figura 2, constituem um grupo de metabólitos isolados durante uma triagem por novos compostos antibióticos em extratos brutos de culturas pouco comuns de myxobacterias do gênero Chondromyces. ${ }^{1}$ Estas myxobacterias foram isoladas em 1994 por Kunze e colaboradores, no GBF (Gesellschaft für Biotechnologische Forshung - Alemanha) a partir de uma amostra de solo coletada na Ilha da Madeira. ${ }^{1,2}$ Nesta triagem, algumas linhagens de Chondromyces crocatus $(\mathrm{Cm}$ c2, Cm c3 e Cm c5) apresentaram potente atividade inibitória sobre o crescimento de algumas bactérias Gram-positivas e uma ampla variedade de leveduras e fungos. Este potencial foi atribuído à presença de um novo grupo de compostos denominados crocacinas.

\footnotetext{
\# Este artigo é dedicado à Profa. Helena M. C. Ferraz por sua valiosa contribuição para a área de síntese orgânica no Brasil.

* e-mail: luciana@iqm.unicamp.br
}

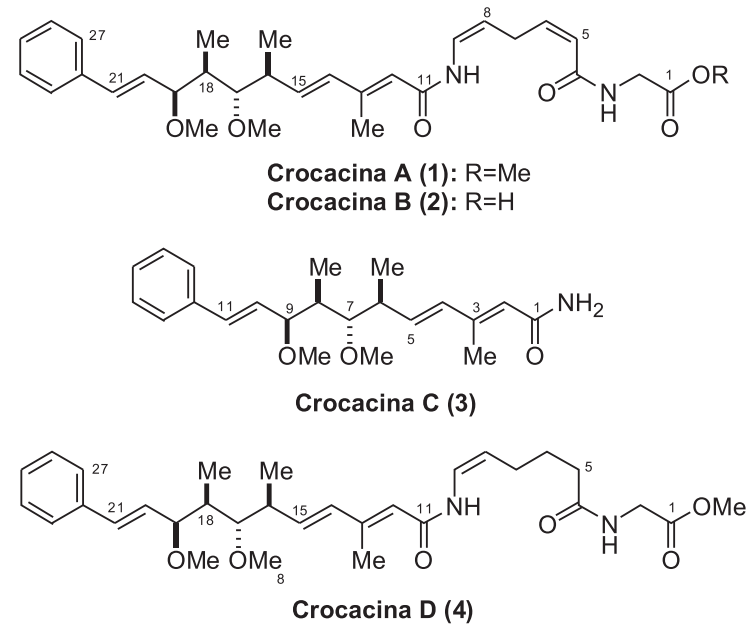

Figura 2. Estruturas das crocacinas A (1), B (2), C (3) e D (4)

As crocacinas A-C são compostos encontrados regularmente em extratos de C. crocatus, sendo a crocacina A (1) o principal componente em culturas agitadas, produzida em rendimentos de cerca de $20 \mathrm{mg} / \mathrm{L}$. A crocacina D (4) foi isolada a partir de extratos de Chondromyces pediculatus e apresentou uma estrutura altamente relacionada à das crocacinas A (1) e B (2), além de apresentar uma atividade destacada dentre as crocacinas sobre o crescimento de microrganismos e sobre culturas de células animais. ${ }^{1,2}$

As crocacinas A, B e D são dipeptídeos pouco comuns derivados de glicina e um ácido 6-aminoexadienóico ou 6aminoexenóico, o qual possui o átomo de nitrogênio protegido por um resíduo policetídico complexo derivado de acila. Este resíduo equivale a um ácido fenilundecatrienóico altamente substituído e encontra-se na forma de amida primária no composto crocacina C. A configuração relativa para as crocacinas foi proposta por Jansen e colaboradores ${ }^{1}$ por estudos de modelagem molecular e por experimentos de nOe. A configuração absoluta para a crocacina C (3) foi recentemente confirmada após sua primeira síntese total ${ }^{3}$ como sendo $6 S, 7 S, 8 R, 9 S$. Até o momento foram relatadas na literatura três sínteses totais para a crocacina $C$ (3), ${ }^{3-5}$ duas sínteses totais para a crocacina A (1) ${ }^{6,7}$ e três sínteses totais para a crocacina $\mathrm{D}(4),{ }^{8-10}$ além de cinco sínteses formais para a crocacina $\mathrm{C}(\mathbf{3}) .^{11-15}$ 


\section{OBJETIVOS}

O objetivo principal deste trabalho de revisão é apresentar as diferentes estratégias sintéticas utilizadas para a construção desta classe de moléculas complexas e mostrar o quanto um trabalho de síntese total exige em termos de versatilidade e criatividade para a proposição das abordagens sintéticas. Além disto, as crocacinas representam uma classe de metabólitos peptídicos modificados, nos quais a estrutura principal é constituída por um resíduo policetídico altamente complexo. Dentre as sínteses apresentadas encontram-se as desenvolvidas em nosso grupo de pesquisas para as crocacinas C e D..$^{5,10}$

\section{ISOLAMENTO ${ }^{1}$}

As crocacinas A (1) - C (3) foram isoladas a partir do extrato de acetona da massa de células úmidas de Chondromyces crocatus. ${ }^{1}$ Após partição inicial em metanol e heptano para remoção dos subprodutos lipofílicos, foram realizadas separações consecutivas em Sephadex LH-20 e sílica gel RP-18. A análise por HPLC-DAD do extrato celular proveniente de uma fermentação em larga escala da linhagem $\mathrm{Cm}$ c5 permitiu a detecção de uma série de metabólitos, sendo a crocacina A (1) o principal componente.

A crocacina D (4) foi detectada por CLAE-FR (cromatografia líquida de alta eficiência - fase reversa) analítico em extratos de Chondromyces pediculatus, linhagem $\mathrm{Cm}$ p17. O composto 4 foi isolado de culturas agitadas por extração simultânea da massa celular e da resina adsorvente Amberlite XAD 16, presente durante o processo de fermentação. Após os constituintes lipofílicos serem removidos por partição em uma mistura de solventes metanolheptano, a crocacina D (4) foi purificada por CLMP-FR (cromatografia líquida de média pressão - fase reversa). ${ }^{1}$

\section{ELUCIDAÇÃO ESTRUTURAL ${ }^{1}$}

As estruturas das crocacinas foram elucidadas a partir da crocacina A (1), o principal produto de C. crocatus. $^{1}$ Análise por espectrometria de massas AR-IE (alta resolução - impacto de elétrons) forneceu o íon molecular $\mathrm{m} / \mathrm{z}$ 538,3042 (calculado: 538,3041) e a composição elementar $\mathrm{C}_{31} \mathrm{H}_{42} \mathrm{~N}_{2} \mathrm{O}_{6}$, implicando em 12 insaturações. $\mathrm{O}$ espectro de UV sugeriu a presença de diferentes grupos cromóforos, apresentando bandas de absorção características em 254 e $291 \mathrm{~nm}$.

O espectro de infravermelho de $\mathbf{1}$ apresentou bandas de absorção intensas em 1747 e $1696 \mathrm{~cm}^{-1}$ indicando a presença de grupos carbonila, além de bandas largas de absorção em 3392 e 3252 $\mathrm{cm}^{-1}$ características da presença de grupos NH.

Os sinais dos espectros de RMN de ${ }^{1} \mathrm{H}$ e $\mathrm{RMN}$ de ${ }^{13} \mathrm{C}$ foram atribuídos e correlacionados por ${ }^{1} \mathrm{H},{ }^{1} \mathrm{H}-\mathrm{COSY}$ e ${ }^{1} \mathrm{H},{ }^{13} \mathrm{C}-\mathrm{HMQC}$ levando à estrutura contendo o núcleo carbônico apresentado na Figura 3. A conectividade entre os fragmentos $\mathrm{A}, \mathrm{B}$ e $\mathrm{C}$ através das ligações das amidas secundárias, além dos resíduos éster e éteres metílicos, foi estabelecida por espectros de correlação a longa distância (HMBC). A configuração $E$ da dupla ligação trissubstituída (C12-C13) foi deduzida através de dados de nOe entre o grupo metila em $\mathrm{C} 13$ com H15 e entre os hidrogênios H12 e H14. ${ }^{2}$ As configurações das duplas ligações dissubstituídas com geometria $Z$ entre C5C6 e C8-C9 e com geometria $E$ entre C14-C15 e C20-C21 foram atribuídas a partir das constantes de acoplamento vicinais ${ }^{3} J_{\mathrm{H} 5-\mathrm{H} 6}(Z)$ $11,4 \mathrm{~Hz}$ [crocacinas A (1) e B (2)], ${ }^{3} J_{\mathrm{H} 8-\mathrm{H} 9}(Z) 8,6 \mathrm{~Hz}$ [crocacinas A (1), B (2) e D (4)], ${ }^{3} J_{\mathrm{H} 14-\mathrm{H} 15}(E) 15,7 \mathrm{~Hz} \mathrm{e}^{3} J_{\mathrm{H} 20-\mathrm{H} 21}(E) 16,2 \mathrm{~Hz}$.

A combinação dos valores das constantes de acoplamento vicinais com as informações extraídas do espectro de NOESY e espectros de nOe permitiu propor a configuração relativa para as

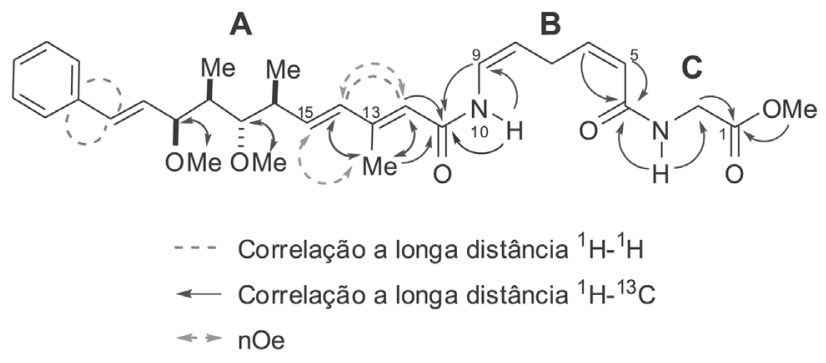

Figura 3. Núcleo da estrutura química das crocacinas ${ }^{l}$

crocacinas como sendo a apresentada na Figura 2. Em adição, cálculos $\mathrm{MM}^{+}$realizados com o método HyperChem ${ }^{16}$ forneceram o confôrmero de menor energia (Figura 4$)^{1}$ contendo os quatro centros estereogênicos ${ }^{17}$ das crocacinas e as suas vizinhanças.

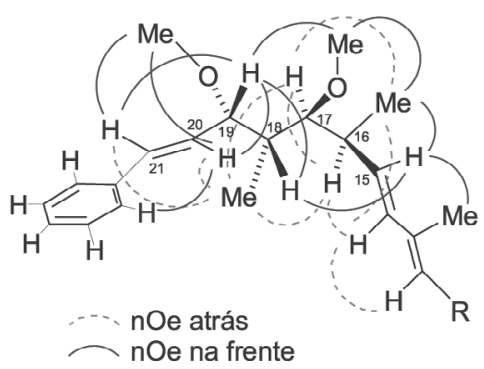

Figura 4. Vista parcial do confôrmero de menor energia das crocacinas e de alguns incrementos de nOe selecionados ${ }^{l}$

De acordo com o modelo, os substituintes dos carbonos assimétricos centrais em $\mathrm{C} 17$ e $\mathrm{C} 18$ aparentemente controlam o arranjo espacial daqueles nos centros assimétricos adjacentes, evitando interações do tipo syn-pentano de alta energia. ${ }^{2}$ Foi observada uma constante de acoplamento ${ }^{3} J_{\mathrm{H} 17-\mathrm{H} 18}=9,5 \mathrm{~Hz}$, típica de uma relação anti-periplanar (anti) de hidrogênios em cadeia carbônica saturada. Um ângulo torsional de $-179^{\circ}$ foi observado através de cálculos de minimização de energia (Tabela 1) para o confôrmero de menor energia, sugerindo que os substituintes nos átomos de carbono assimétricos centrais, ou seja, a metoxila em C17 e a metila em C18 apresentam uma posição relativa anti.

Tabela 1. Ângulos de torsão calculados ${ }^{\mathrm{a}}$ e constantes de acoplamento vicinais no segmento $\mathrm{C} 15-\mathrm{C} 20$ das crocacinas

\begin{tabular}{lccccc}
\hline Hidrogênios & 15,16 & 16,17 & 17,18 & 18,19 & 19,20 \\
\hline$\varphi\left(^{\circ}\right)$ & -175 & -55 & -179 & 64 & -37 \\
${ }^{3} J_{\mathrm{H}, \mathrm{H}}(\mathrm{Hz})$ & 8.1 & 2.2 & 9.5 & 2.5 & 7.1 \\
\hline
\end{tabular}

${ }^{\mathrm{a}}$ Cálculos $\mathrm{MM}^{+}$realizados com HyperChem 5.1 e ChemPlus 2.0. ${ }^{16}$

Nesta conformação, a metoxila em C17 dirige tanto a metila em C16 como o substituinte em C15 para posições synclinais e similarmente, a metila em C18 faz com que o grupo metila da metoxila em C19 e o substituinte em C20 ocupem posições synclinais. Conseqüentemente, os hidrogênios com relação anti dos carbonos centrais, H17 e H18, apresentam relação syn com os hidrogênios vicinais, H16 e H19. Foram observados valores pequenos de constante de acoplamento ${ }^{3} J_{\mathrm{H} 16-\mathrm{H} 17}=2,2 \mathrm{~Hz}$ e ${ }^{3} J_{\mathrm{H} 18-\mathrm{H} 19}=2,5$ $\mathrm{Hz}$, mostrando boa concordância com os correspondentes ângulos de torsão calculados para o modelo, de $-55^{\circ}$ e $64^{\circ}$, respectivamente. Foram calculados ângulos de torsão de $175^{\circ}$ entre $\mathrm{H} 15$ e $\mathrm{H} 16$ e $-37^{\circ}$ entre $\mathrm{H} 19$ e $\mathrm{H} 20$, apresentando novamente boa correlação 
com as constantes de acoplamento vicinais observadas para os hidrogênios em questão $\left({ }^{3} J_{\mathrm{H} 15-\mathrm{H} 16}=8,1 \mathrm{~Hz}\right.$ e $\left.{ }^{3} J_{\mathrm{H} 19-\mathrm{H} 20}=7,1 \mathrm{~Hz}\right)$.

A análise dos espectros de RMN de nOe e ROESY de $\mathbf{1}$ foi utilizada para confirmar o arranjo espacial dos hidrogênios e dos grupos metila na cadeia. Assim como esperado para o modelo, foram observados incrementos de nOe entre os pares de hidrogênios com relação syn (H16-H17 e H18-H19) e os outros incrementos de nOe observados (alguns omitidos na Figura 4) também permitiram uma boa correlação com a conformação de menor energia para as crocacinas. A partir das informações apresentadas, foi possível estabelecer a configuração relativa anti-anti-syn $(16 S, 17 S, 18 R, 19 S)$ para os compostos da série das crocacinas (numeração para A, B e D).

A crocacina B (2), componente mais polar da série, foi identificada como o ácido carboxílico livre pela análise conjunta dos espectros de RMN, do íon molecular encontrado por HR-EI $(\mathrm{m} / \mathrm{z}$ 524,2849, calculado: 524,2886) e a composição elementar apresentada $\mathrm{C}_{30} \mathrm{H}_{40} \mathrm{~N}_{2} \mathrm{O}_{6}$, indicando a ausência da metoxila da função éster.

A estrutura da crocacina $\mathrm{C}$ (3) foi derivada de sua composição elementar $\mathrm{C}_{22} \mathrm{H}_{31} \mathrm{NO}_{3}$ correspondendo ao íon molecular $\mathrm{m} / \mathrm{z}$ 357,2309 (calculado: 357,2304), além da ausência de todos os sinais referentes ao fragmento contendo o aminoácido insaturado e do resíduo proveniente do éster da glicina em $\mathbf{1}$. No espectro de IV foram observadas bandas de absorção em 1655 e $1600 \mathrm{~cm}^{-1}$, características de amidas primárias.

A estrutura da crocacina D (4), isolada de C. pediculatus, foi atribuída como sendo similar à estrutura 1, entretanto foi observado um íon molecular de $\mathrm{m} / \mathrm{z}$ 540,3179 (calculado: 540,3199) e composição elementar $\mathrm{C}_{31} \mathrm{H}_{44} \mathrm{~N}_{2} \mathrm{O}_{6}$, indicando dois átomos de hidrogênio a mais que a crocacina $\mathrm{A}$ (1). A ausência da dupla ligação $Z$ entre C5 e C6 foi confirmada por comparação entre os espectros de $\mathrm{RMN}$ de ${ }^{1} \mathrm{H}$, nos quais os sinais olefínicos foram trocados por dois novos conjuntos de sinais de hidrogênios metilênicos em 2,26 e $1,67 \mathrm{ppm}$ no espectro de $\mathrm{RMN}$ de ${ }^{1} \mathrm{H}$, correspondendo aos sinais em 34,5 e 26,1, respectivamente, no espectro de RMN de ${ }^{13} \mathrm{C}$.

As crocacinas representam um novo grupo de dipeptídeos lineares isolados a partir de $C$. crocatus. A crocacina $\mathrm{C}$ (3) é um fragmento estrutural de $\mathbf{1}, \mathbf{2}$ e 4, apesar de pequenas quantidades de $\mathbf{3}$ serem observadas regularmente no extrato de $C$. crocatus. Esta estrutura pode ser adicionalmente formada durante o processo de isolamento por clivagem da ligação enamida, sensível a condições ácidas.

\section{PROPRIEDADES BIOLÓGICAS}

A atividade biológica das crocacinas foi avaliada por testes de difusão em ágar, utilizando discos de papel. A crocacina A (1) inibiu moderadamente o crescimento de algumas bactérias Gram-positivas e apresentou potente inibição sobre o crescimento de várias leveduras e fungos. ${ }^{1}$

Com um MIC (concentração inibitória mínima) de 1,4 ng/mL a crocacina D (4) de $C$. pediculatus apresentou uma atividade biológica bastante distinta das outras crocacinas sobre culturas de Saccharomyces cerevisiae (crescimento em meio livre de glicose), comparado ao MIC de $10 \mathrm{mg} / \mathrm{L}$ para $\mathbf{1}, 100 \mathrm{mg} / \mathrm{L}$ para 3 e $12,5 \mu \mathrm{g} / \mathrm{mL}$ para $\mathbf{2}$. A ordem de toxicidade observada sobre culturas de células de fibroblasto de camundongo $\mathrm{L} 929\left(\mathrm{IC}_{50}\right)$ foi de $0,06 \mathrm{mg} / \mathrm{mL}$ para 4 comparado a $0,2 \mathrm{mg} /$ $\mathrm{L}$ para $\mathbf{1}, 40 \mathrm{mg} / \mathrm{L}$ para 2 e $140 \mathrm{mg} / \mathrm{L}$ para 3.

Kunze e colaboradores ${ }^{1}$ observaram que culturas de $S$. cerevisiae se tornaram menos sensíveis às crocacinas quando cultivadas na presença de glicose. Sabendo-se que culturas de $S$. cerevisiae são capazes de metabolizar açúcares por fermentação, o efeito antagônico da glicose sugere que as crocacinas possam interferir no mecanismo do processo respiratório. Um estudo mais detalhado sobre o metabolismo de ação das crocacinas revelou que a inibição do crescimento de fungos e leveduras é causada pelo bloqueio do fluxo de elétrons ao longo do segmento citocrômico $b$-cl (complexo III) do sistema de transporte de elétrons da cadeia respiratória. ${ }^{1}$

A crocacina D (4) mostrou-se o composto mais ativo da série das crocacinas sendo provavelmente o sistema $(Z)$-enamida responsável pela atividade biológica apresentada, já que a crocacina C (3) é essencialmente inativa.

O modo de ação apresentado pelas crocacinas A (1) e D (4) sobre o crescimento de fungos despertou o interesse de Crowley e colaboradore ${ }^{18}$ em sintetizar análogos nos quais a alta complexidade da cadeia lateral foi substituída por subunidades aromáticas mais simples e contendo funcionalidades que pudessem mimetizar as encontradas nas estruturas das crocacinas. Apesar dos análogos apresentarem maior estabilidade fotoquímica que os produtos naturais, eles continuaram a ter tempos de meia-vida relativamente curtos na superfície das plantas, o que provavelmente se deve à instabilidade fotoquímica da função (Z)-enamida e infelizmente nenhum dos compostos foi ativo o suficiente para estudos posteriores.

Alguns estudos têm mostrado que compostos que apresentam a função enamida, como a salicilialamida A (Salicylihalamide) (5) ${ }^{19}$ - (Figura 5), um produto natural isolado de esponjas marinhas que apresentou uma potente atividade anti-tumoral, tornam-se inativos quando este grupo é quimicamente modificado, por exemplo, pela saturação da dupla ligação. Algumas especulações a respeito do modo de ação indicam que ocorre a protonação do grupo enamida seguida pelo ataque nucleofílico ao íon $\mathrm{N}$-acilimínio resultante para formar uma enzima conjugada. ${ }^{20}$

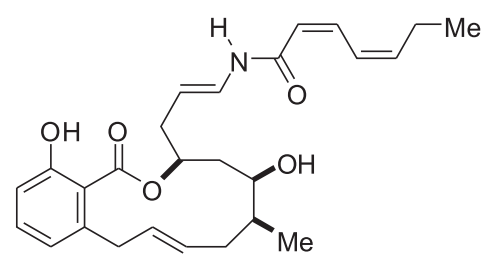

Salicilialamida A (5)

Figura 5. Estrutura da salicilialamida A (5)

\section{SÍNTESES TOTAIS DA (+)-CROCACINA C}

\section{Síntese de Rizzacasa e colaboradores ${ }^{3}$}

A primeira síntese total relatada na literatura para a crocacina $C$ (3) foi realizada pelo grupo de Rizzacasa ${ }^{3}$ em 2000 e confirmou a estereoquímica relativa proposta para o produto natural. A análise retrossintética (Esquema 1) mostra que a porção dienamida (ligação C3-C4) de 3 pode ser construída a partir de uma reação de acoplamento cruzado de Stille ${ }^{21}$ entre o iodeto vinílico 6 e a vinilestanana 7.22 A ligação C8-C9 seria introduzida através de uma reação aldólica assimétrica syn (controle do substrato) ${ }^{23}$ entre a cetona quiral 8 e o cinamaldeído (9), com os centros estereogênicos com estereoquímica relativa anti-anti-syn sendo estabelecidos por uma reação de redução estereosseletiva $a n t i^{24}$ do aduto aldólico obtido.

A sequiência foi iniciada com a reação aldólica entre o enolato de estanho gerado a partir da etilcetona $\mathbf{8}^{25}$ e o cinamaldeído (9) levando ao aduto de aldol 1,2-syn-1,4-syn $\mathbf{1 0}$ em $86 \%$ de rendimento e $97 \%$ de excesso diastereoisomérico - ed (Esquema 2). Esta reação aldólica, controlada pelo substrato, ocorre via um estado de transição cíclico quelado, no qual o estanho se encontra coordenado à carbonila do aldeído, ao oxigênio do enolato e ao oxigênio protegido pelo grupo $p$-metoxibenzila (-PMB), com a face $S i$ do enolato reagindo com a face $R e$ do aldeído ${ }^{23}$ e levando ao 


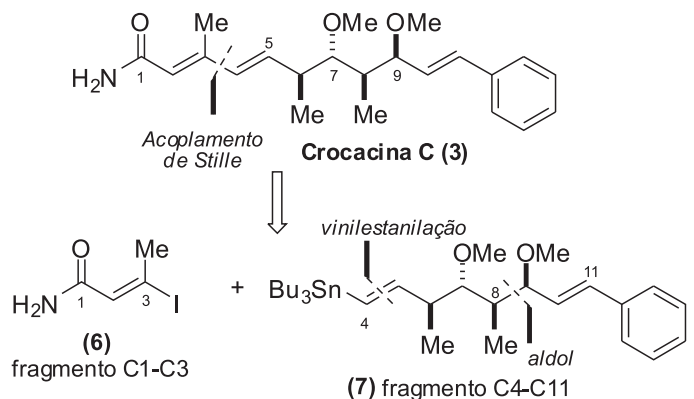<smiles>C=CCCCCC(C)C(=O)CC</smiles>

Esquema 1. Planejamento retrossintético de Rizzacasa e colaboradores para a obtenção da crocacina $C(\mathbf{3})^{3}$

aduto aldólico $\mathbf{1 0}$ desejado, com excelente diastereosseletividade e rendimento. A reação de redução estereosseletiva da carbonila em 10 foi realizada utilizando-se triacetoxiboroidreto de tetrabutilamônio $\left(\mathrm{Me}_{4} \mathrm{NBH}(\mathrm{OAc})_{3}\right)$ fornecendo o diol 1,3-anti $11 \mathrm{em}$ $96 \%$ de rendimento e $97 \%$ de excesso diastereoisomérico. ${ }^{26}$ Metilação das hidroxilas em C7 e C9 utilizando KH como base seguida por tentativa de remoção do éter $p$-metoxibenzílico em C5 com 2,3-dicloro-5,6-diciano-1,4-benzoquinona (DDQ) $)^{27}$ forneceu a cetona 12 resultante de uma reação indesejada de demetoxilação oxidativa regiosseletiva. Nesta reação ocorreu a abstração de hidreto mediada pelo DDQ no sítio alílico conjugado ao invés do sítio benzílico desejado, levando à formação de um cátion alílico altamente estabilizado, o qual pode ser capturado pela água. A saída subsequiente de $\mathrm{MeOH}$ promoveu a formação de $\mathbf{1 2}$.

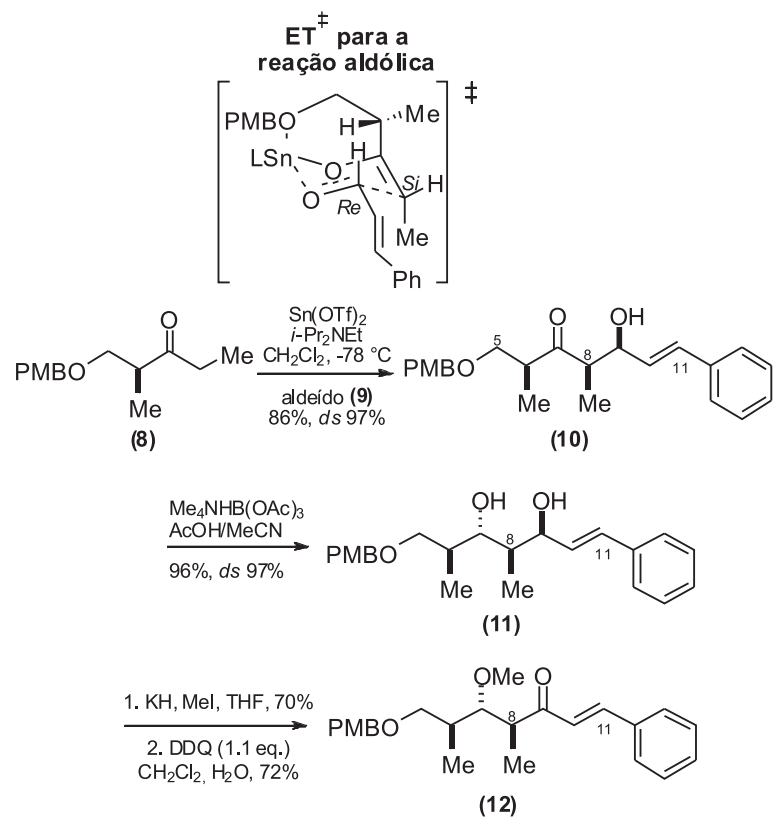

Esquema 2. Formação da cetona 12

A alternativa adotada para contornar a reação de oxidação alílica indesejada foi diminuir a densidade eletrônica em C9 promovendo-se a acetilação do diol 11 (84\%), conduzindo à fomação do diacetato o qual pôde ser desprotegido com DDQ (81\%) sem problemas (Esquema 3). A hidroxila primária resultante foi novamente protegida com cloreto de $t$-butildifenilsilila (TBDPSCl, 87\%) levando ao diacetato 13. Após remoção dos acetatos com hidreto de di-isobutilalumínio (DIBALH, 88\%), as hidroxilas secundárias foram metiladas (70\%) e a hidroxila primária desprotegida utilizando fluoreto de tetra $n$ butilamônio (TBAF) para fornecer o álcool primário 14 (100\%). Reação de oxidação com a periodinana de Dess-Martin ${ }^{28}$ forneceu o aldeído correspondente, o qual foi submetido à reação de vinil-estanilação mediada por crômio segundo a metodologia de Hodgson, ${ }^{29}$ conduzindo a vinilestanana 7 em $75 \%$ de rendimento para as duas etapas.
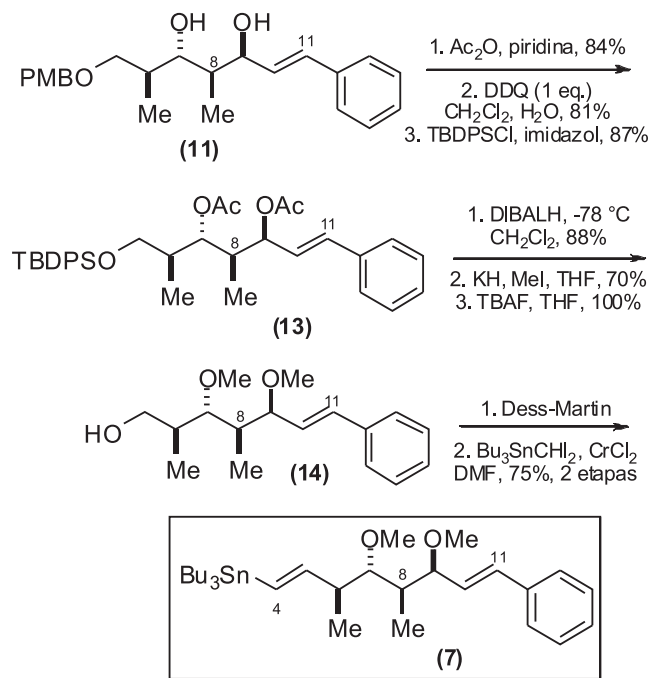

Esquema 3. Obtenção da estanana vinílica (7)

O iodeto 6, necessário para o acoplamento de Stille, foi preparado a partir do ácido tetrólico $\mathbf{1 5}$ - (Esquema 4). Adição de $\mathrm{HI}$ a $90{ }^{\circ} \mathrm{C}$ levou à formação do ácido carboxílico com configuração $Z$, o qual foi isomerizado para uma mistura de isômeros $E: Z$ na proporção de 70:30 após aquecimento a $135{ }^{\circ} \mathrm{C} .{ }^{30}$ Após esterificação do ácido com diazometano, o éster 16 com configuração $E$ (na sua forma pura) ${ }^{31}$ reagiu com $\mathrm{AlMe}_{3}$ e $\mathrm{NH}_{4} \mathrm{Cl}^{32}$ levando a formação do iodeto vinílico desejado 6 como um sólido cristalino em $52 \%$ de rendimento.

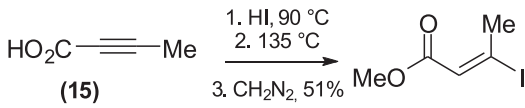

(16)

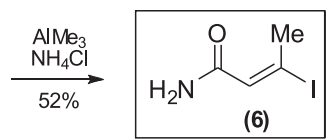

Esquema 4. Obtenção do iodeto vinílico 6

Finalmente, tratamento de uma solução da vinilestanana 7 e iodeto vinílico 6 em $\mathrm{N}$-metil pirrolidinona (NMP) com quantidades catalíticas de tris-dibenzilidenoacetona dipaládio $\left(\mathrm{Pd}_{2}(\mathrm{dba})_{3}\right)$ e trifurilfosfina (TFP) a $50{ }^{\circ} \mathrm{C}$ forneceu a (+)-crocacina $\mathrm{C}(\mathbf{3}) \mathrm{em}$ $51 \%$ de rendimento - (Esquema 5), que apresentou dados físicos e espectroscópicos idênticos ao produto natural. ${ }^{3} \mathrm{O}$ valor de rotação ótica $\left([\alpha]_{\mathrm{D}}{ }^{18}+61,3(c 0,3, \mathrm{MeOH})\right)$ apresentou boa concordância com o valor observado para o produto natural $\left([\alpha]_{\mathrm{D}}^{22}+52,2(c 0,3\right.$, $\mathrm{MeOH})$ ), confirmando a estereoquímica absoluta proposta para as crocacinas durante seu isolamento. ${ }^{1}$

A síntese da (+)-crocacina C (3) por Rizzacasa e colaboradores requereu 14 etapas a partir do $(S)$-3-hidróxi-2-metilpropanoato de metila (comercialmente disponível) para a sequiência linear mais longa em $7,4 \%$ de rendimento global. 
<smiles>CC(I)=CC(N)=O</smiles>

(6)<smiles>COC(/C=C/c1ccccc1)C(C)C(OC)C(C)/C=C/[Sn](C)(C)C</smiles>

(7)

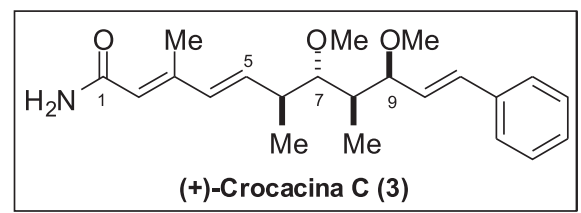

Esquema 5. Síntese total da (+)-crocacina C (3)

\section{Síntese de Chakraborty e colaboradores ${ }^{4}$}

A segunda síntese total da (+)-crocacina C (3) foi relatada pelo grupo de Chakraborty, ${ }^{4}$ em 2001. O planejamento retrossintético mostra que a (+)-crocacina $C(3)$ pode ser obtida a partir da união entre o aldeído 17 e o dietilfosfonato $\mathbf{1 8}^{33}$ por uma reação de olefinação de Horner-Wadsworth-Emmons (Esquema 6). Os centros assimétricos em C8-C9 foram gerados por uma reação aldólica diastereosseletiva mediada por $\mathrm{Ti}(\mathrm{IV})^{34}$ enquanto os centros estereogênicos em C6-C7 foram obtidos por uma reação de epoxidação assimétrica de Sharpless ${ }^{35}$ seguida por uma reação de abertura de epóxido mediada por dimetilcuprato de lítio $\left(\mathrm{Me}_{2} \mathrm{CuLi}\right)$.<smiles>C/C=C/[C@@H](C)C(C(C)/C=C/C(C)=C/C(N)=O)C(C)[C@@H](/C=C/c1ccccc1)OC</smiles>
Horner-Emmons Crocacina C (3)<smiles>CCOC(=O)C=C(C)CP(=O)(OCC)OCC</smiles>

(18)

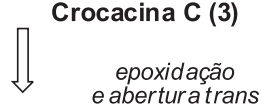

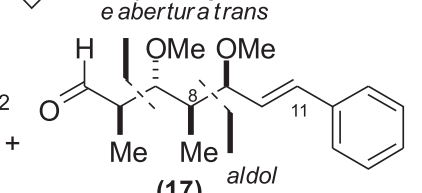

(17)

Esquema 6. Planejamento retrossintético de Chakraborty e colaboradores para a obtenção da (+)-crocacina $C(3)^{4}$

A seqüência reacional inicia-se com a reação aldólica assimétrica entre o enolato de Ti(IV) derivado da $N$-aciloxazolidinotiona $1^{34}$ e o cinamaldeído (9), fornecendo o aduto aldólico syn 20 como único diastereoisômero em $89 \%$ de rendimento (Esquema 7). Redução controlada de 20 com 1 equivalente de DIBALH forneceu o aldeído intermediário, ${ }^{36} \mathrm{o}$ qual reagiu com o ilídeo de fósforo estabilizado conduzindo ao éster $\alpha, \beta$-insaturado 21 (70\%, 2 etapas). Redução da função éster com excesso de DIBALH (85\%) seguida por proteção da hidroxila primária com cloreto de $t$-butildimetilsilila (TBSCl), forneceu o álcool homoalílico 22, no qual a hidroxila secundária foi metilada e a hidroxila primária desprotegida conduzindo ao álcool alílico 23 em $64 \%$ de rendimento para as últimas 3 etapas.

$\mathrm{O}$ álcool alílico $\mathbf{2 3}$ foi submetido à reação de epoxidação assimétrica de Sharpless ${ }^{35}$ utilizando (-)-di-isopropiltartarato ((-)DIPT), Ti(O'PrO $)_{4}$ e hidroperóxido de terc-butila (TBHP), conduzindo ao epóxi-álcool 24 como único diastereoisômero em $93 \%$ de rendimento (Esquema 8). Abertura regiosseletiva de $\mathbf{2 4}$ utilizando $\mathrm{Me}_{2} \mathrm{CuLi}$ forneceu o 1,3-diol como produto principal em $86 \%$ de rendimento. ${ }^{37}$ A sequiência de reações de proteção, metilação e desproteção foi novamente repetida levando ao álcool 14 (64\%,
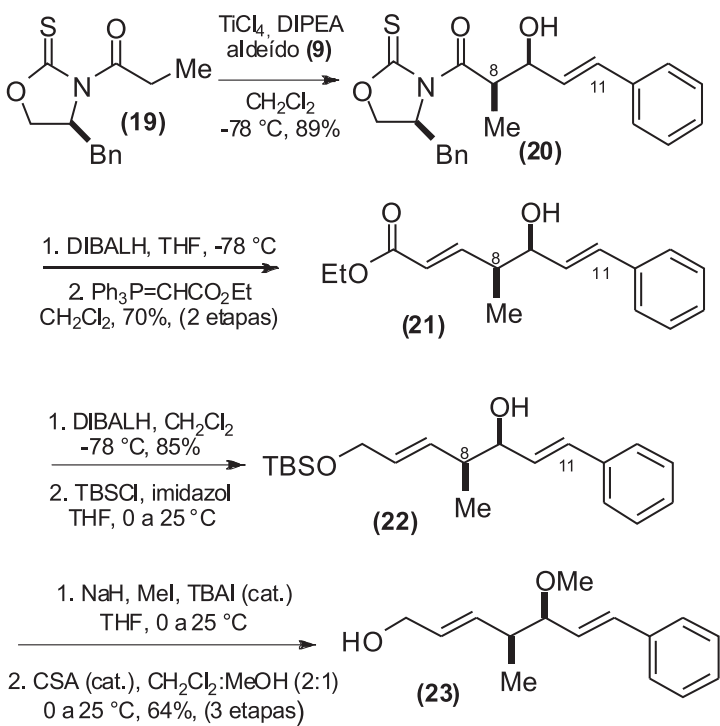

TBAI: iodeto de $n$-tetrabutil amônio CSA: ácido cânforsulfônico

Esquema 7. Obtenção do álcool alílico 23

etapas), também obtido na rota anterior, o qual foi oxidado com $\mathrm{SO}_{3}$-piridina fornecendo o aldeído $\mathbf{1 7}$ em $96 \%$ de rendimento.
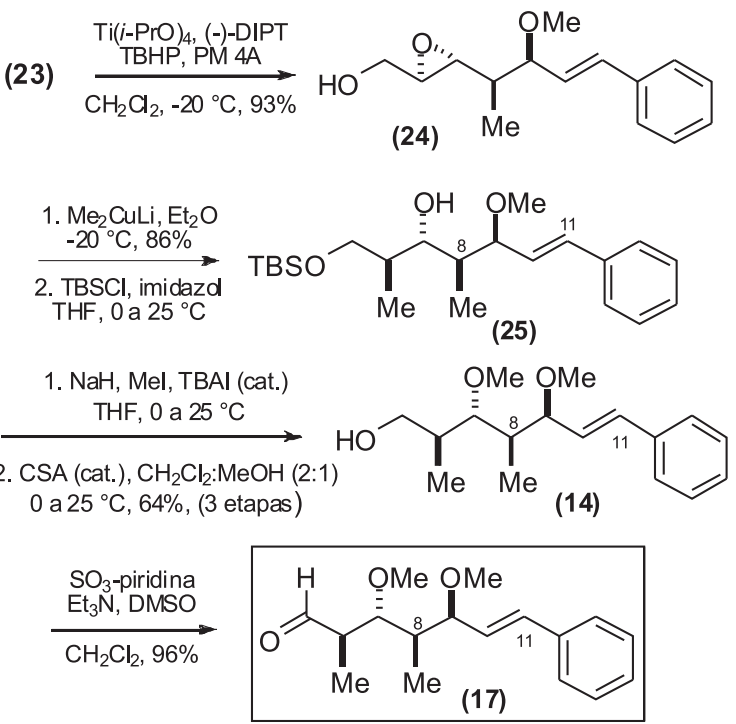

Esquema 8. Obtenção do aldeído 17

Reação de Horner-Wadsworth-Emmons ${ }^{38}$ entre o aldeído 17 e o dietilfosfonato $\mathbf{1 8}^{39}$ (Esquema 9) forneceu a olefina $\mathbf{2 6}$ em 60\% de rendimento (recuperação de $20 \%$ do aldeído de partida). O éster 26 foi então conduzido à (+)-crocacina C (3) após saponificação seguida por conversão do ácido carboxílico resultante na respectiva amida, através da formação do anidrido misto (66\%, 2 etapas).

Fazendo-se uma comparação entre a abordagem sintética desta rota com a utilizada por Rizzacasa podemos observar que a última apresenta um caráter ligeiramente mais linear, levando à obtenção da (+)-crocacina C (3) em 6,2\% de rendimento para um total de 16 etapas, a partir da $\mathrm{N}$-aciloxazolidinationa $19 .{ }^{4}$

\section{Síntese de Dias e colaboradores}

A terceira estratégia sintética para obtenção da (+)-crocacina 
<smiles>CCOC(=O)C=C(C)CP(=O)(OCC)OCC</smiles><smiles>CCOC(=O)C=C(C)C=CC(C)C(OC)C(C)C(C)OC</smiles>

(26)

$$
\begin{aligned}
& \text { 1. } \mathrm{LiOH} \\
& \text { THF:MeOH: } \mathrm{H}_{2} \mathrm{O} \\
& 0 \text { a } 25^{\circ} \mathrm{C} \\
& \text { 2. } \mathrm{Et}_{3} \mathrm{~N}, \mathrm{ClCO}_{2} \mathrm{Et} \\
& \mathrm{THF}, \mathrm{NH}_{4} \mathrm{OH} 25 \% \\
& -20 \text { a } 0{ }^{\circ} \mathrm{C}, 66 \% \text { (2 etapas) }
\end{aligned}
$$

LDA: diisopropilamideto de lítio

DMPU: 1,3-dimetil-3,4,5,6-tetra-hidro-2(1H)-pirimidinona

Esquema 9. Síntese total da (+)-crocacina C (3)

C (3) foi descrita por Dias e colaboradores, ${ }^{5}$ também em 2001. A análise retrossintética (Esquema 10) mostra que a porção dienoamida em 3 pode ser clivada, levando aos fragmentos correspondentes às porções $E$-vinilestanana 27 e iodeto vinílico $\mathbf{2 8}$ contendo os quatro centros estereogênicos, conectados via uma reação de acoplamento cruzado de Stille. Os centros em C6 e C7 podem ser construídos via abertura estereosseletiva do epóxido $\mathbf{3 0}$ com cuprato de alta ordem e os centros em C8 e C9, estabelecidos através de uma reação aldólica mediada por enolato de boro.

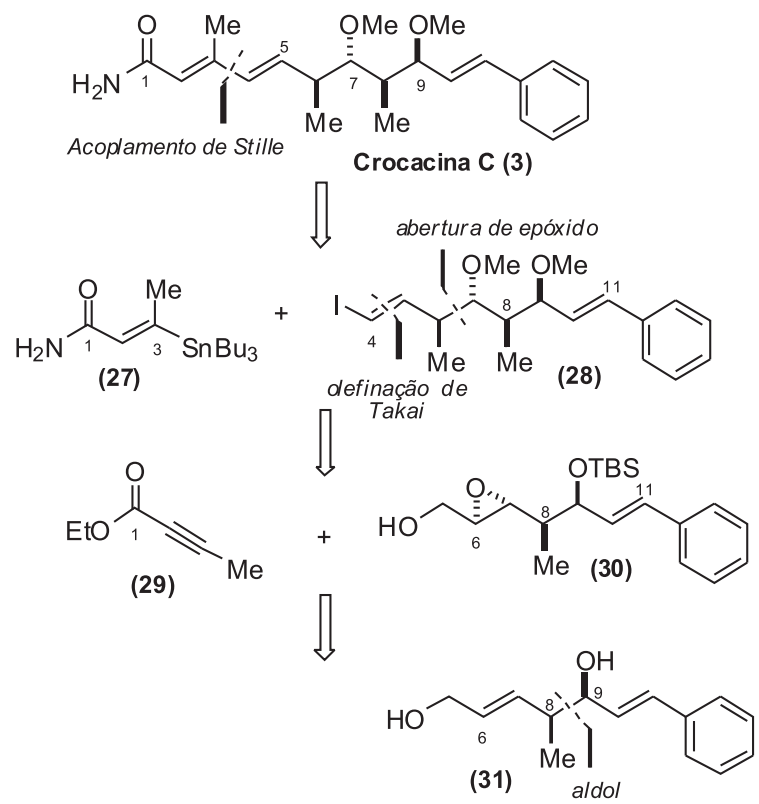

Esquema 10. Planejamento retrossintético de Dias e colaboradores para a obtenção da (+)-crocacina $C(3)^{5}$

A rota sintética inicia-se com a reação aldólica assimétrica entre o enolato de boro gerado a partir da $N$-propioniloxazolidinona $(R)-(-)$ (32), (preparada por acilação da correspondente $(R)-(+)$-oxazolidinona) $)^{40}$ e o cinamaldeído (9), conduzindo ao aduto aldólico 33 em $85 \%$ de rendimento e diastereosseletividade > 95,05 - (Esquema 11). Na seqüência, foi realizada uma reação de transamidação utilizando as condições descritas por Weinreb. ${ }^{32,41}$ Tentativas de proteção da hidroxila secundária na presença de triflato de $t$-butildimetilsilila (TBSOTf) e 2,6-lutidina ou cloreto de trietilsilila (TESCl) e imidazol levaram à formação exclusiva da amida de Weinreb $\alpha, \beta, \gamma, \delta$-insaturada
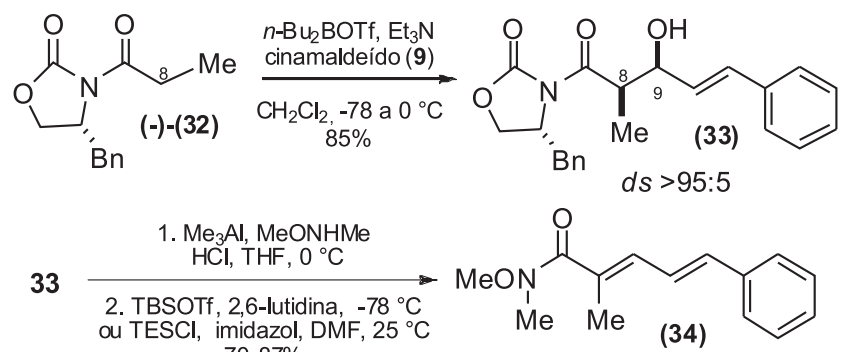
$70-87 \%$
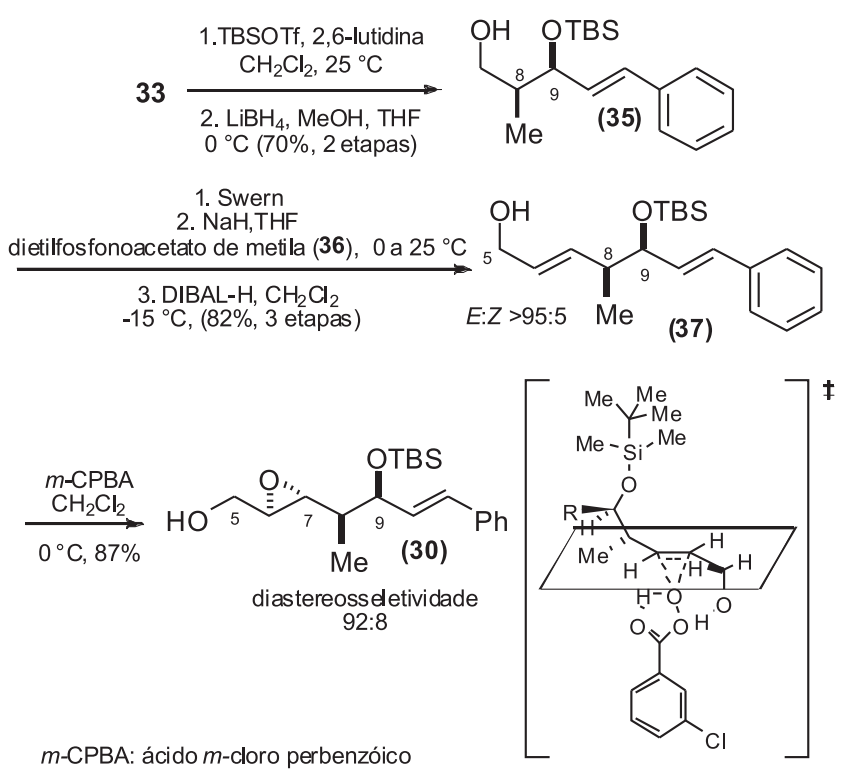

Esquema 11. Obtenção do intermediário epóxido 30

34. Alternativamente, o aduto aldólico 33 foi convertido ao álcool primário 35. Para isto a hidroxila secundária em $\mathbf{3 3}$ foi protegida utilizando-se TBSOTf e 2,6-lutidina e posterior clivagem redutiva do auxiliar quiral conduziu ao álcool primário $\mathbf{3 5} \mathrm{em} 70 \%$ de rendimento para 2 etapas. A hidroxila primária em $\mathbf{3 5}$ foi oxidada nas condições de $S_{w e r n}{ }^{42}$ e o aldeído bruto foi utilizado em um acoplamento de Horner-Wadsworth-Emmons com o $\beta$-cetofosfonato estabilizado, dietilfosfonoacetato de metila 36 , para fornecer o éster $\alpha, \beta$-insaturado o qual foi tratado na sequiência com 2 equivalentes de DIBALH produzindo o álcool alílico 37 em $82 \%$ de rendimento para as três etapas (Esquema 11). A etapa seguinte envolveu uma reação de epoxidação régio- e diastereosseletiva do álcool alílico 37 utilizando a metodologia descrita por Isobe e Miyashita. ${ }^{43,44} \mathrm{O}$ epóxido 30 foi obtido com alta régio- e diastereosseletividade (ed 92:08) em $87 \%$ de rendimento.

Reação de abertura trans-seletiva do epóxido 30, promovida pelo cuprato de alta ordem $\mathrm{Me}_{2} \mathrm{CuCNLi}_{2},{ }^{45}$ levou regiosseletivamente ao produto desejado $\mathbf{3 8}$ com estereoquímica anti-anti-syn em $90 \%$ de rendimento (Esquema 12). Uma seqüência de desproteção e proteção seletiva da hidroxila primária forneceu 39 (86\%, 2 etapas), que após metilação das hidroxilas secundárias e remoção do protetor -TBDPS na hidroxila primária forneceu o intermediário $\mathbf{1 4}$, comum a todas as rotas em $96 \%$ de rendimento para as últimas 2 etapas. O iodeto vinílico $\mathbf{2 8}$ com geometria $E$ foi obtido após reação de oxidação da função álcool com a periodinana de Dess-Martin, seguido por reação de olefinação de Takai $(63 \%, 2$ etapas) (Esquema 12).

A E-vinilestanana 27 necessária para o acoplamento de Stille foi obtida a partir do éster acetilênico 29, seguindo a metodologia de Piers e colaboradores (Esquema 13). ${ }^{46} \mathrm{O}$ éster $E$-tributilestanil$\alpha, \beta$-insaturado 40 (obtido em $70 \%$ de rendimento a partir de 29 ) 


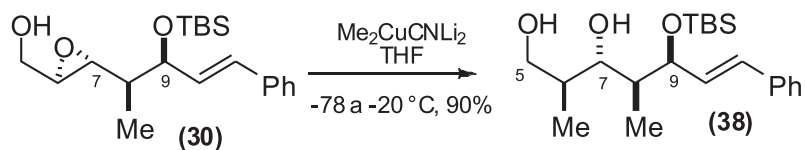

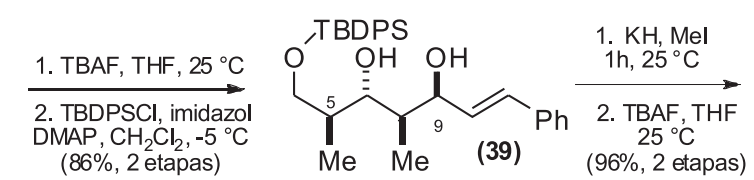

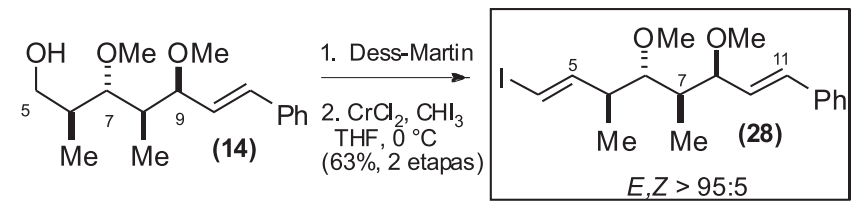

DMAP: 4-dimetilamino piridina

Esquema 12. Obtenção do (E)-iodeto vinílico 28

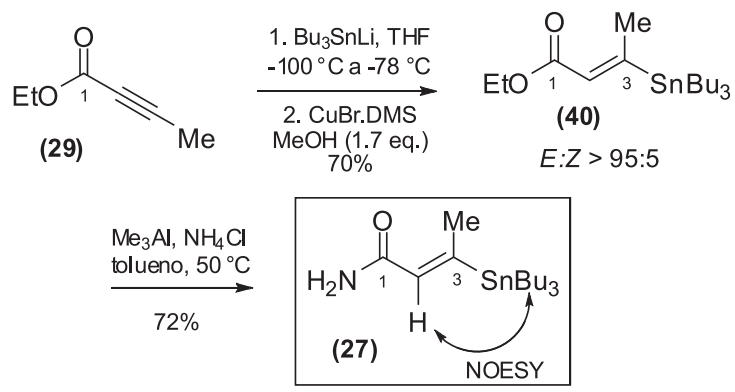

Esquema 13. Obtenção da estanana vinílica 27

foi convertido na amida 27 por tratamento com $\mathrm{Me}_{3} \mathrm{Al}, \mathrm{NH}_{4} \mathrm{Cl}$ em tolueno a $50{ }^{\circ} \mathrm{C}(72 \%) .^{32}$

Para concluir a síntese os fragmentos $\mathbf{2 7}$ e $\mathbf{2 8}$ foram conectados via uma reação de acoplamento cruzado de $S_{\text {tille }}^{21,47}$ na presença de $\mathrm{Pd}_{2} \mathrm{dba}_{3}, \mathrm{CuCl}(\mathrm{I}), \mathrm{AsPh}_{3}$ em THF a $50^{\circ} \mathrm{C}$, levando à obtenção da (+)crocacina C (3) em 75\% de rendimento (Esquema 14). A rota sintética descrita requer 15 etapas para a seqüência linear mais longa, a partir de 32 e leva ao produto final em 17\% de rendimento global.<smiles>COC(/C=C/c1ccccc1)C(C)C(C)C(C)/C=C/I</smiles><smiles>CO[C@@H](C(C)/C=C/C(C)=C/C(N)=O)[C@H](C)[C@@H](/C=C/c1ccccc1)OC</smiles>

Condições:

a. $\mathrm{Pd}_{2}(\mathrm{dba})_{3}, \mathrm{NMP}, \mathrm{AsPh}_{3}, 60^{\circ} \mathrm{C}, 69 \%$

b. $\mathrm{Pd}_{2}(\mathrm{dba})_{3}, \mathrm{THF}, \mathrm{CuCl}(\mathrm{I}), \mathrm{AsPh}_{3}, 50{ }^{\circ} \mathrm{C}, 75 \%$

\section{Esquema 14. Sintese total da (+)-crocacina C (3)}

Comparando-se as três rotas relatadas, podemos observar que todos os autores utilizam reações aldólicas para a construção dos centros com estereoquímica relativa syn em C8-C9. Rizzacasa ${ }^{3}$ utilizou uma reação aldólica de Paterson controlada pelo substrato, enquanto Chakraborty ${ }^{4}$ e Dias ${ }^{5}$ utilizaram auxiliares quirais para induzir a quiralidade em $\mathrm{C} 8$ e C9. Também nos dois últimos trabalhos, os centros em C7 e C8 foram obtidos via reação de epoxidação seguida por abertura regiosseletiva do epóxido formado utilizando cuprato. Entretanto, Chakraborty faz uso da epoxidação de Sharpless, a qual utiliza um ligante quiral para gerar a seletividade desejada, que apesar de extremamente eficiente, encarece o processo. Já Dias faz uso de uma reação de epoxidação induzida pelo substrato, utilizando ácido $m$-cloroperbenzóico ( $m$-CPBA) e garante a alta diastereosseletividade observada, tornando esta etapa uma alternativa mais viável. A utilização do acoplamento de Stille como etapa final, torna o processo geral mais convergente. ${ }^{5}$

\section{SÍNTESES TOTAIS DA (+)-CROCACINA D}

\section{Síntese de Rizzacasa e colaboradores ${ }^{8}$}

A primeira síntese total da crocacina D (4) foi relatada em 2002 por Rizzacasa e colaboradores, ${ }^{8}$ confirmando a configuração absoluta para o composto isolado de $C$. pediculatus. A crocacina D (4) apresenta como grande desafio sintético à construção do sistema (Z)-enamida, devido à elevada sensibilidade deste grupo funcional. O planejamento retrossintético proposto envolve a acilação ${ }^{48}$ entre o ânion derivado do $(Z)$-enecarbamato 41 e o respectivo fragmento acil-policetídico (Esquema 15).

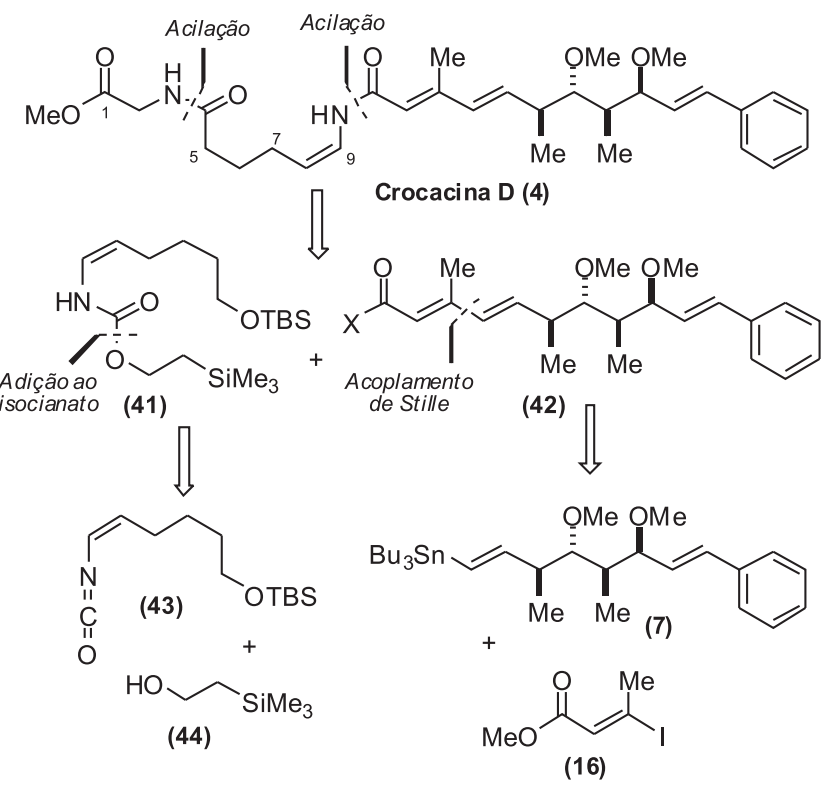

Esquema 15. Planejamento retrossintético de Rizzacasa para obtenção da crocacina $D(4)^{8}$

Na síntese total descrita por Rizzacasa para a crocacina $C(3)$ o problema encontrado com a desproteção do éter-PMB levou à formação de 12, ocasionando a necessidade de manipulações desnecessárias de grupos de proteção e estendendo a rota sintética (Esquema 2). Como alternativa, para a síntese total da crocacina D foi efetuada a troca do grupo protetor da etilcetona quiral de partida para triisopropilsilil (TIPS - Esquema 16). ${ }^{49}$ Como resultado, foi observada diminuição da diastereosseletividade na reação aldólica mediada por $\mathrm{Sn}(\mathrm{II})$ e controlada pelo substrato (de $97 \%$ ed para $88 \%$ ed), com o aduto de aldol $\mathbf{4 6}$ sendo obtido em $88 \%$ de rendimento e $88 \%$ de diastereosseletividade. ${ }^{23}$ No entanto, as etapas sintéticas foram reduzidas de 11 para 7 (a partir do $(S)$-3-hidróxi-2metilpropanoato de metila) para a obtenção do intermediário 14. O 


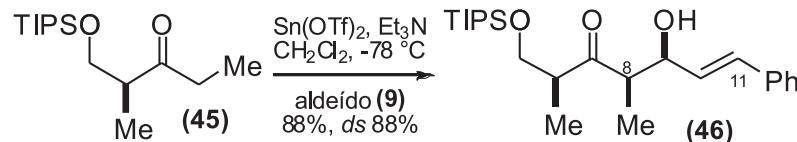

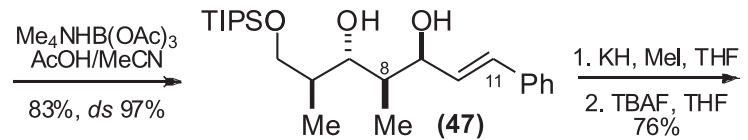<smiles>COC(/C=C/[Sn](C)(C)C)C(C)C(OC)C(C)/C=C/[Sb](C)(C)C</smiles><smiles>[TeH]</smiles><smiles>COC(=O)/C=C(C)/C=C/C(C)C(OC)C(C)C(C)/C=C/c1ccccc1</smiles>

Esquema 16. Obtenção do dieno-éster 48

álcool 14 foi convertido à estanana 7 (88\%, 2 etapas), a qual participou de uma reação de acoplamento de Stille ${ }^{21,47,50}$ com o iodeto vinílico 16, fornecendo o dieno-éster 48 em $80 \%$ de rendimento.

$\mathrm{O}(Z)$-enecarbamato 41 foi obtido a partir do aldeído 49 - (Esquema 17). Reação de Horner-Wadsworth-Emmons entre 49 e o fosfonato $\mathbf{5 0} \mathbf{5}^{51}$ forneceu o éster $(Z)$ - $\alpha, \beta$-insaturado que após hidrólise conduziu ao ácido carboxílico $\mathbf{5 1}$ em $69 \%$ de rendimento para duas etapas. Tratamento de $\mathbf{5 1}$ com difenilfosforilazida (DPPA) e $\mathrm{NaH}^{52}$ resultou na formação da $N$-acilazida intermediária (Z:E 5,7:1, 68\%), que foi aquecida a $110{ }^{\circ} \mathrm{C}$ para fornecer o $(Z)$-vinilisocianato 43 ,

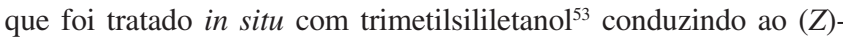
enecarbamato $41 \mathrm{em}$ bons rendimentos.

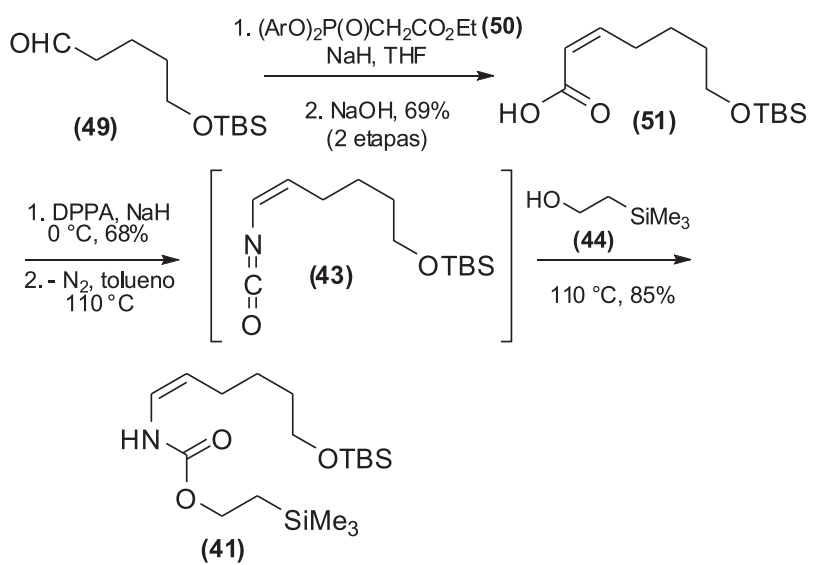

Esquema 17. Obtenção do (Z)-enecarbamato 41

O éster 48 foi hidrolisado para ácido carboxílico, o qual foi convertido para o respectivo sal de sódio e tratado com cloreto de oxalila (Esquema 18). Uma solução do ânion derivado de 41 foi adicionada ao cloreto de ácido fornecendo a enamida $\mathbf{5 2}$ (30\%, 2 etapas). Reação de desproteção seletiva da hidroxila primária $(91 \%),{ }^{54}$ seguida por oxidação em duas etapas (Dess-Martin ${ }^{28} \mathrm{e}$ Pinnick ${ }^{55}$ ) conduziu ao ácido carboxílico 53. Finalmente, acoplamento peptídico com o éster metílico da glicina $54^{56} \mathrm{e}$ desproteção do nitrogênio forneceu a crocacina D (4) (48\% de rendimento para a sequiência de 4 etapas) que apresentou dados físicos e espectroscópicos idênticos aos descritos na literatura para o composto, confirmando a configuração absoluta proposta $\left([\alpha]_{\mathrm{D}}{ }^{20}+102,7\right.$ $\left(c\right.$ 0,22, MeOH); lit. $\left.^{1}[\alpha]_{\mathrm{D}}{ }^{20}+109,6(c 0,56, \mathrm{MeOH})\right)$.

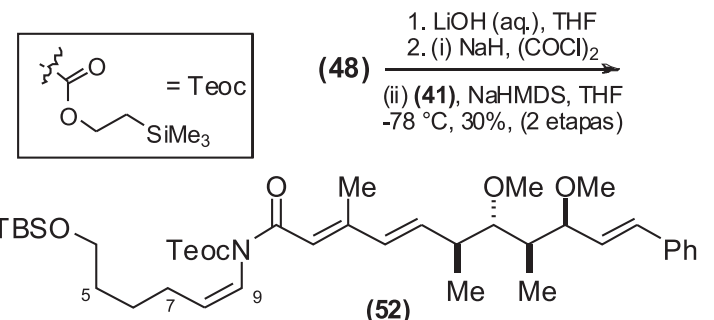

(52)

$$
\begin{aligned}
& \text { 1. HF-piridina, piridina } \\
& \text { THF, } 25^{\circ} \mathrm{C}, 91 \% \\
& \text { 2. Dess-Martin, piridina }
\end{aligned}
$$<smiles>CO[C@H](/C=C/c1ccccc1)C(C)[C@H](OC)C(C)/C=C/C(C)=C/C(=O)N(/C=C\CCCC(=O)O)C(=O)[O-]</smiles>

1. DPPA, $\mathrm{NaHCO}_{3}, \mathrm{ClH}_{3} \mathrm{~N}\left(\mathrm{CH}_{2}\right) \mathrm{CO}_{2} \mathrm{Me}$ (54) $71 \%$ (3 etapas)

2. TBAF, THF, $0{ }^{\circ} \mathrm{C}, 68 \%$

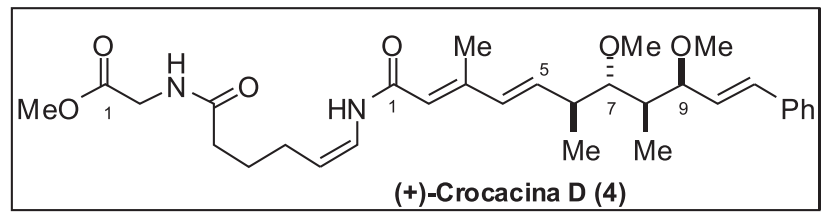

Esquema 18. Sintese total da (+)-crocacina $D(4)$

A abordagem sintética desenvolvida requereu 18 etapas a partir do $(S)$-3-hidróxi-2-metilpropanoato de metila e levou à formação da (+)-crocacina D (4) em $2,4 \%$ de rendimento. ${ }^{8}$

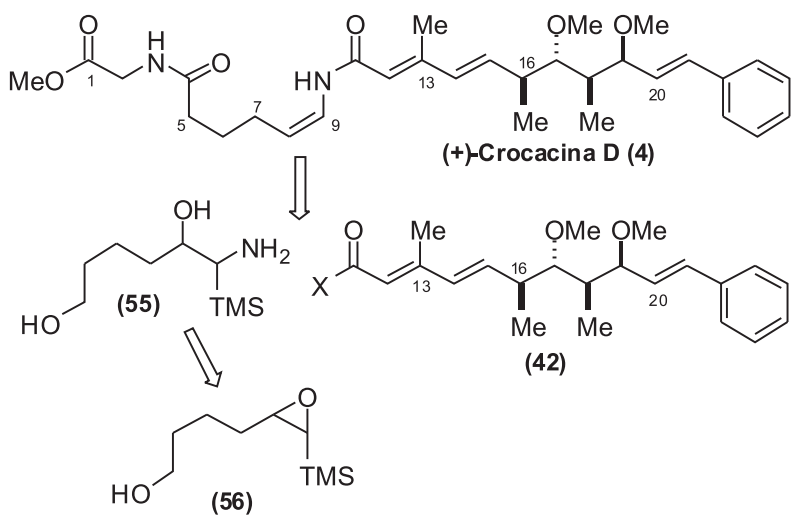

Esquema 19. Planejamento retrossintético de Chakraborty para obtenção da crocacina $D(4)^{9}$

\section{Síntese de Chakraborty e colaboradores}

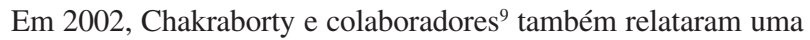
rota sintética para a obtenção da (+)-crocacina D (4). Nesta rota, a estratégia adotada para a construção da função $(Z)$-enamida é baseada na abertura regiosseletiva do epóxido sililsubstituído $\mathbf{5 6}$ com um íon azida, ${ }^{57}$ seguido por reação de eliminação de Peterson ${ }^{58}$ do $\alpha$-azido- $\beta$-hidroxialquilsilano resultante (Esquema 19).

A rota inicia-se com a transformação do álcool monoprotegido 57 ao produto acetilênico sililado 58 (Esquema 20). Nesta sequiência de reações a hidroxila primária é oxidada para aldeído, seguido por olefinação utilizando $\mathrm{PPh}_{3}$ e $\mathrm{CBr}_{4}$ para levar à dibromolefina, a qual conduz à formação de um acetileto de Li após tratamento com 


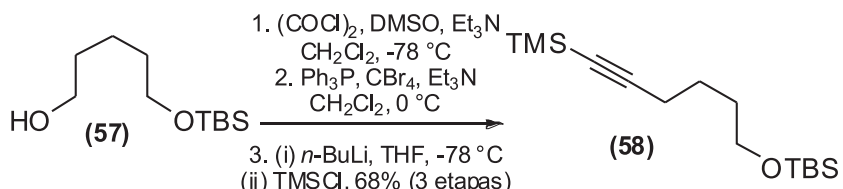

(ii) TMSCl, $68 \%$ (3 etapas)
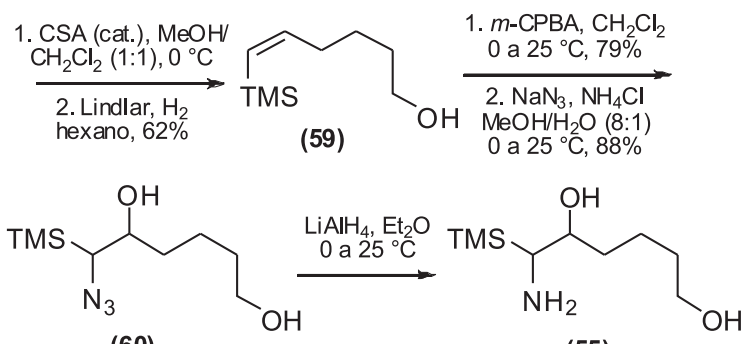

(60)

(55)

Esquema 20. Obtenção do $\alpha$-amido- $\beta$-hidroxialquilsilano 55

n-BuLi, que é então sililado na presença de clorotrimetilsilano (TMSCl), (68\%, 3 etapas). Desproteção do grupo -TBS em MeOH/ $\mathrm{CH}_{2} \mathrm{Cl}_{2}$ na presença de quantidades catalíticas de ácido canforsulfônico (CSA), seguida por hidrogenação do acetileno utilisando catalisador de Lindlar, ${ }^{59}$ forneceu o $(Z)$-vinilsilano 59 em $62 \%$ de rendimento. Tratamento de $\mathbf{5 9} \mathrm{com} \mathrm{m}$-CPBA conduziu a um epóxido intermediário (79\%) que, frente à azida de sódio, forneceu regiosseletivamente o $\alpha$-azido- $\beta$-hidroxialquilsilano 60 (88\%). Redução da azida com $\mathrm{LiAlH}_{4}$ forneceu a amina 55 necessária para o acoplamento peptídico.

Reação de acoplamento peptídico entre o ácido carboxílico $\mathbf{6 1}$, preparado na rota para obtenção da (+)-crocacina C (3) a partir do éster 26 (Esquema 9) e a amida 55, forneceu o composto $\mathbf{6 2} \mathrm{em}$ $57 \%$ de rendimento para 2 etapas (Esquema 21). Reação de olefinação de Peterson conduziu à $(Z)$-enamida de interesse 63 (96\%), mas tentativas de oxidação da hidroxila livre para o ácido em duas etapas $\left(\right.$ Swern ${ }^{42}$ e Pinnick ${ }^{55}$ ) não conduziram ao ácido carboxílico desejado. A formação do aldeído foi confirmada, mas o produto da segunda etapa não continha a dupla ligação entre C8-<smiles>COC(/C=C/c1ccccc1)C(C)[C@@H](OC)[C@@H](C)/C=C/C(C)=C/C(=O)O</smiles>

(61)<smiles>COC(/C=C/c1ccccc1)C(C)[C@H](OC)C(C)/C=C/C(C)=C/C(=O)NC(C(C)C)C(O)CCCCO</smiles><smiles>CO[C@@H]([C@@H](C)/C=C/C(C)=C/C(=O)N/C=C\CCCCO)[C@H](C)[C@@H](/C=C/c1ccccc1)OC</smiles>

(63)

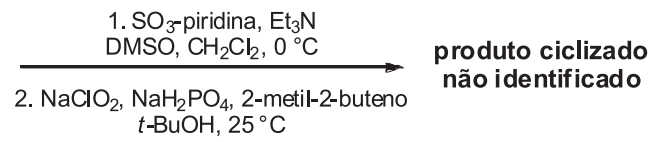

HOBt: 1-hidroxibenzotriazol

Esquema 21. Tentativa de oxidação de 63
C9 de acordo com os dados de RMN de ${ }^{1} \mathrm{H}$. Os dados preliminares sugeriram que o composto formado parecia se tratar de uma lactona resultante de reação de ciclização intramolecular.

Para contornar o problema, a reação de olefinação de Peterson foi adiada para a última etapa da síntese, após incorporação do fragmento proveniente do éster metílico da glicina (54). Desta forma, o diol 62 foi submetido à seqüência de proteção-desproteção seletiva para fornecer o álcool primário $64 \mathrm{em} 55 \%$ de rendimento para duas etapas (Esquema 22). Oxidação em duas etapas resultou na formação do ácido carboxílico $\mathbf{6 5}$ (74\%, 2 etapas). A reação de acoplamento peptídico foi realizada via formação do anidrido misto por tratamento do ácido carboxílico $\mathbf{6 5}$ com cloroformiato de isobutila na presença de $N$-metilmorfolina (NMM), seguido por adição do éster metílico da glicina (54) para fornecer $66 \mathrm{em} 77 \%$ de rendimento. Desproteção da hidroxila secundária com TBAF forneceu o oxiânion intermediário que promoveu a reação de olefinação de Peterson in situ, conduzindo à (+)-crocacina D (4) com o sistema ( $Z$ )-enamida instalado com total estereosseletividade em $78 \%$ de rendimento. A (+)-crocacina D (4) foi sintetizada em 22 etapas a partir da $N$-aciloxazolidinotiona 19 em 1,3\% de rendimento. ${ }^{9}$
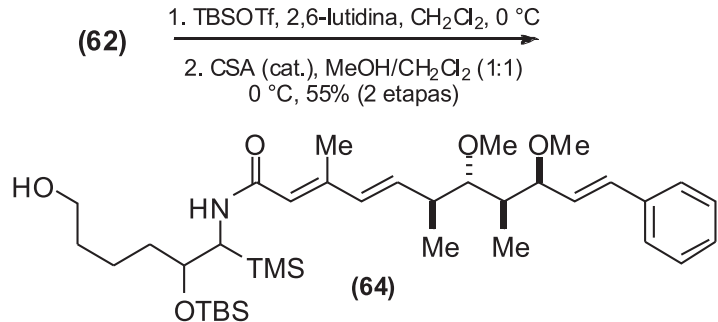

1. $\mathrm{SO}_{3}$-piridina, $\mathrm{Et}_{3} \mathrm{~N}$ DMSO, $\mathrm{CH}_{2} \mathrm{Cl}_{2}, 0^{\circ} \mathrm{C}$

2. $\mathrm{NaClO}_{2}, \mathrm{NaH}_{2} \mathrm{PO}_{4}, 2$-metil-2-buteno $t-\mathrm{BuOH}, 25^{\circ} \mathrm{C}, 74 \%$ (2 etapas)

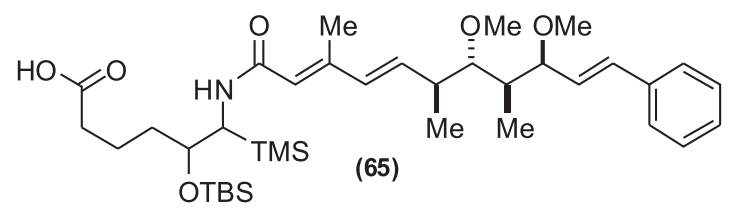

$$
\begin{aligned}
& \text { (i) cloroformiato de isobutila } \\
& \mathrm{NMM}, \mathrm{CH}_{2} \mathrm{Cl}_{2}, 0{ }^{\circ} \mathrm{C}
\end{aligned} \underset{\text { (ii) (54), DIPEA, DMF }}{ }
$$

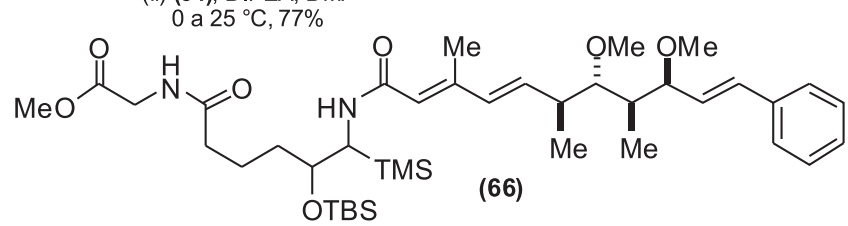

$$
\underset{0 \text { a } 25{ }^{\circ} \mathrm{C}, 78 \%}{\stackrel{\text { TBAF, THF }}{\longrightarrow}}(+) \text {-Crocacina D (4) }
$$

Esquema 22. Síntese total da (+)-crocacina D (4) por Chakraborty e colaboradores

\section{Síntese de Dias e colaboradores ${ }^{10}$}

Em 2005, Dias e colaboradores ${ }^{10}$ divulgaram sua estratégia para a síntese total da crocacina D. A análise retrossintética mostra que a crocacina $\mathrm{D}$ pode ser obtida por uma reação de acoplamento cruzado mediada por $\mathrm{Cu}(\mathrm{I})^{60}$ entre a crocacina $\mathrm{C}(3)$ e o $(Z)$-iodeto vinílico 67, o qual pode ser obtido a partir do 1,3-propanodiol (Esquema 23).

A preparação da cadeia lateral da crocacina D (4) foi iniciada a 
<smiles>C=CC(=O)OC(=O)OC(=O)OC</smiles>

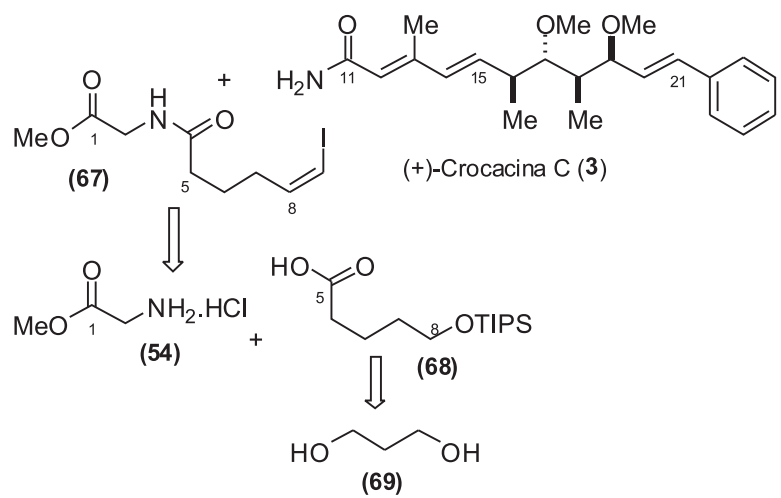

Esquema 23. Planejamento retrossintético de Dias para obtenção da (+)crocacina $D(4)^{10}$
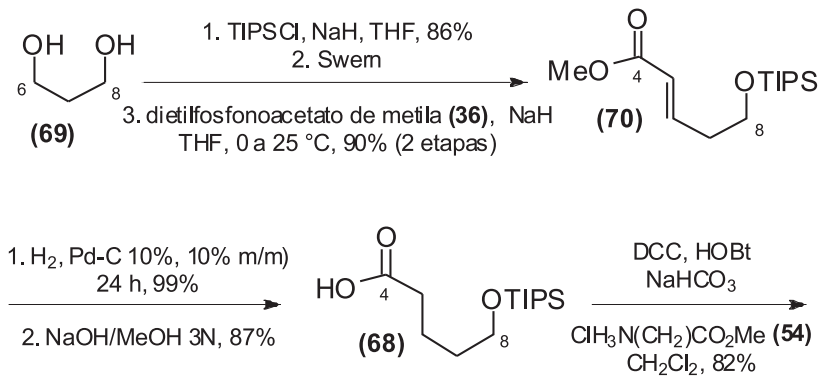<smiles>COC(=O)CNC(=O)CCCCOC(F)(F)F</smiles>

(71)

DCC: 1,3-dicicloexil carbodiimida

Esquema 24. Obtenção do segmento peptídico 71

partir do 1,3-propanodiol 69 (Esquema 24) com a seqüência de reações de monoproteção, oxidação e homologação de HornerWadsworth-Emmons fornecendo o éster- $\alpha, \beta$-insaturado $70 \mathrm{em} 77 \%$ de rendimento (3 etapas). Após reação de hidrogenação catalítica (99\%) e hidrólise do éster, o ácido carboxílico $\mathbf{6 8}$ foi obtido em $87 \%$ de rendimento. Acoplamento com o éster metílico da glicina (54) forneceu o segmento peptídico 71, derivado de glicina e ácido pentanóico $(82 \%)$.

Seqüência de proteção do nitrogênio (90\%) e desproteção da hidroxila primária em $\mathbf{7 1}(83 \%)$ conduziu ao amidoalquilcarbamato 72 (Esquema 25). A hidroxila primária em 72 foi oxidada utilizando-se Dess-Martin e o aldeído resultante participou de uma reação de Wittig na presença de iodometiltrifenilfosfônio (73) fornecendo o iodeto vinílico 74 com geometria $Z$ (> 95:5 Z:E, 81\%, 2 etapas). Desproteção do nitrogênio após tratamento com ácido trifluoroacético forneceu o iodeto vinílico $\mathbf{6 7}$, necessário para a reação de acoplamento cruzado em $85 \%$ de rendimento.

A única etapa restante para finalizar a síntese total da (+)crocacina D (4) envolve a reação de acoplamento cruzado mediado por $\mathrm{Cu}(\mathrm{I})$ entre o fragmento 67 e a (+)-crocacina $\mathrm{C}(3)$. Esta reação foi conduzida na presença de $N, N$-dimetilglicina e $\mathrm{Cs}_{2} \mathrm{CO}_{3}$ em
(71)

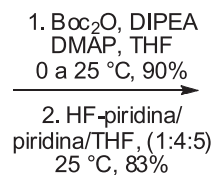<smiles>COC(=O)CN(C(=O)CCCO)C(=O)OCc1ccccc1</smiles>

(72)
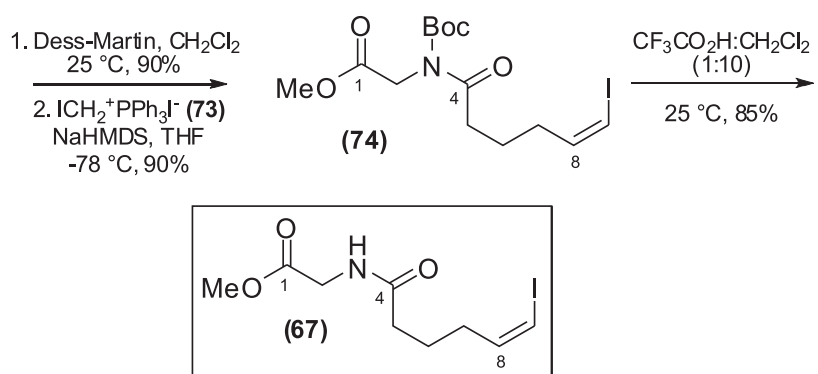

NaHMDS: hexametildissililazida de sódio

Esquema 25. Preparação da cadeia lateral da (+)-crocacina D (4)<smiles>CO[C@H](C(C)[C@@H](/C=C/c1ccccc1)OC)[C@@H](C)/C=C/C(C)=C/C(N)=O</smiles>

(+)-Crocacina C (3)
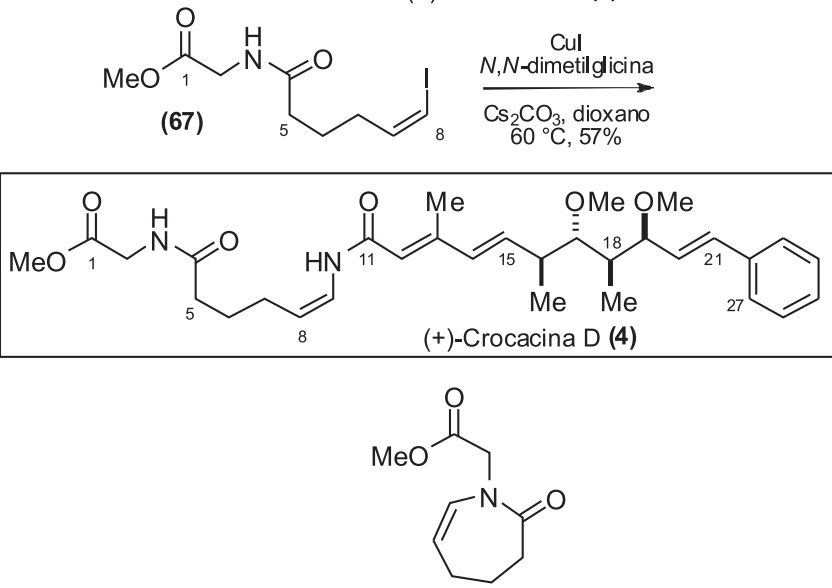

(75)

sub-produto

Esquema 26. Síntese total da (+)-crocacina D (4) por Dias e colaboradores

dioxano, de acordo com o protocolo descrito por Ma ${ }^{60}$ Por esta aproximação a (+)-crocacina D (4) foi obtida em $57 \%$ de rendimento, juntamente com o enecarbamato $\mathbf{7 5}$, resultante da ciclização intramolecular de 67 (Esquema 26). Esta aproximação permitiu a síntese total da (+)-crocacina D (4) em 16 etapas em 10\% de rendimento global, correspondendo à rota mais convergente e com mellhor rendimento químico até então apresentada para a obtenção de $4 .^{10}$

\section{SÍNTESES TOTAIS DA (+)-CROCACINA A}

\section{Síntese de Rizzacasa e colaboradores}

A primeira síntese total assimétrica da crocacina A foi descrita em 2003 por Rizzacasa e colaboradores. ${ }^{6}$ As etapas chave desta síntese envolvem os mesmos tipos de reações utilizadas para a inserção da cadeia lateral da crocacina $\mathrm{D} .{ }^{8} \mathrm{~A}$ análise retrossintética (Esquema 27) mostra que a ligação peptídica N3-C4 pode ser construída por acoplamento peptídico, enquanto a instalação altamente desafiadora da funcionalidade $(Z, Z)$-enamida poderia ser 
<smiles>C=C/C=C\C/C=C\NC(=O)/C=C(\C)C=CC(C)C(OC)C(C)C(C)OC</smiles><smiles>COC(=O)CNCC(C)(C)C</smiles>

(76)<smiles>C=CCC#CCC#CCO[Sb](C)(=O)=O</smiles>

(79)

Esquema 27. Planejamento retrossintético de Rizzacasa para obtenção da (+)-crocacina $A(\mathbf{1})^{6}$

realizada por reação de acilação ${ }^{48,53}$ do ânion derivado do $(Z, Z)$ dienocarbamato 77 e o cloreto de ácido 76 (formado na rota da Crocacina $\mathrm{D}(3)$ - Esquema 18). O dienocarbamato seria formado pela adição de trimetilsililetanol ao isocianato de vinila 78, obtido por rearranjo de Curtius da correspondente $(Z, Z)$ - $N$-acilazida, a qual por sua vez poderia ser obtida por redução parcial do 1,4-diino 79, seguido por oxidação e formação da acilazida.

A síntese do (Z,Z)-dienocarbamato 77 foi realizada a partir do álcool 80, ${ }^{61}$ o qual foi convertido ao mesilato $81(81 \%)$ e partici-
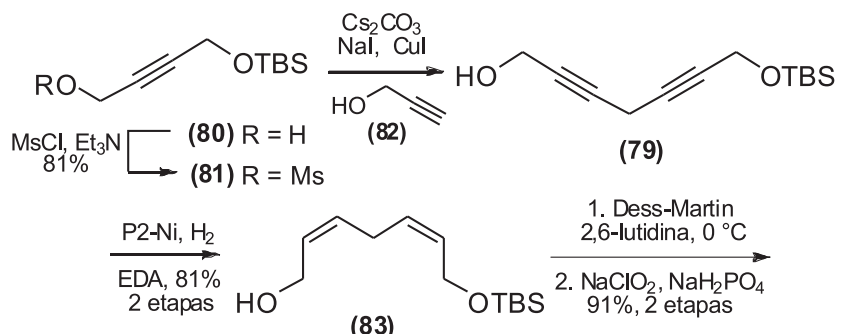

(83)
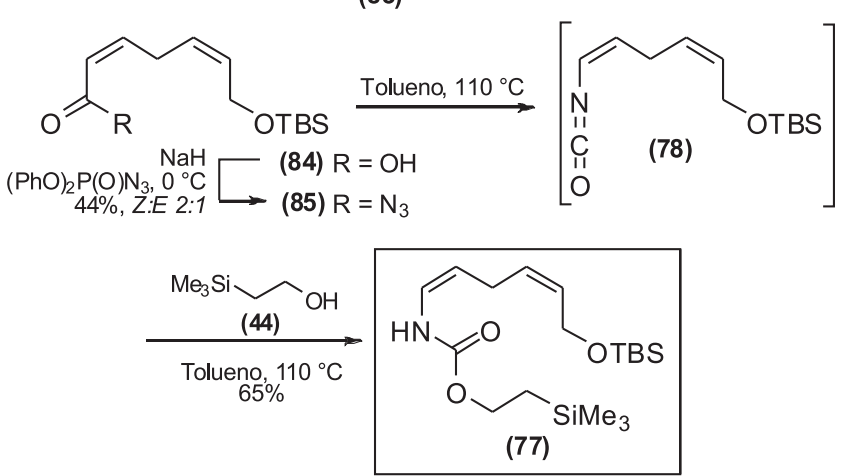

Esquema 28. Obtenção do (Z,Z)-dienocarbamato 77 pou de um acoplamento mediado por $\mathrm{Cu}(\mathrm{I})$ com o álcool propargílico (82) fornecendo o 1,4-diino $\mathbf{7 9}^{62}$ (Esquema 28). Redução parcial de $\mathbf{7 9}$ para o $(Z, Z)$-1,4-dieno $\mathbf{8 3}$ (81\%, 2 etapas) foi realizada utilizando o catalisador recém preparado P-2 Ni ("Ni boroidreto reduzido") sob atmosfera de hidrogênio na presença de etilenodiamina (EDA). ${ }^{63}$ A hidroxila em $\mathbf{8 3}$ foi oxidada em duas etapas (Dess-Martin/Pinnick) para ácido carboxílico (91\%, etapas) e este foi convertido à $(Z, Z)-N$-acilazida 85 nas condições de Kitahara $^{64}(44 \%)$, permitindo a minimização na isomerização da dupla ligação. Tratamento de $\mathbf{8 5}$ sob aquecimento forneceu o isocianato intermediário 78, o qual foi refluxado em tolueno e reagiu in situ com trimetilsililetanol (44) para fornecer o dienocarbamato 77 em $65 \%$ de rendimento (Esquema 28).

Com o dienocarbamato em mãos, o ânion de $\mathbf{7 7}$ foi gerado na presença de hexametildissililazida de sódio (NaHMDS) e este foi adicionado ao cloreto de ácido $76^{3} \mathrm{em}$ THF, a $-78{ }^{\circ} \mathrm{C}$ fornecendo a (Z,Z)-dienamida 86 protegida com 2-trimetilsililetilcarbamato (Teoc - Esquema 29). Esta reação forneceu 86 em 37\% de rendimento (52\% baseando-se no ácido carboxílico recuperado). O protetor -TBS foi removido seletivamente na presença do Teoc utilizandose HF-piridina em piridina $(87 \%)^{54}$ e o álcool resultante foi oxidado a aldeído com Dess-Martin tamponado com 2,6-lutidina ${ }^{28}$ para evitar a isomerização do alceno conjugado. Após oxidação para ácido (82\%, 2 etapas), o produto $\mathbf{8 8}$ foi tratado com TBAF para remoção do grupo Teoc. O ácido carboxílico resultante foi acoplado ao éster metílico da glicina $(\mathbf{5 4})^{56}$ para fornecer a crocacina A (1), que apresentou dados físicos e espectroscópicos idênticos aos descritos na literatura para o produto natural $\left([\alpha]_{D}{ }^{19}+126,8(c 0,077\right.$, $\mathrm{MeOH})$; lit. $\left.{ }^{1}[\alpha]_{\mathrm{D}}{ }^{22}+109,6(c 1,0, \mathrm{MeOH})\right)$, entretanto em baixo rendimento (2,0 $\mathrm{mg} ; 23 \%$ para duas etapas). Esta rota sintética permitiu a obtenção de 1 em 15 etapas a partir do (S)-3-hidróxi-2metilpropanoato de metila e $2,3 \%$ de rendimento global. ${ }^{6}$

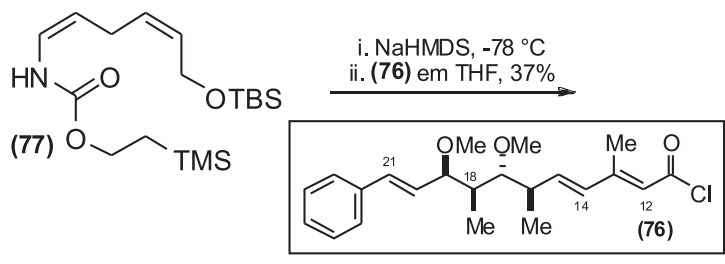<smiles>[R]OC/C=C\C/C=C\N(C(=O)C=C(C)/C=C/C(C)C(OC)C(C)C(/C=C/c1ccccc1)OC)C(=O)OC</smiles>
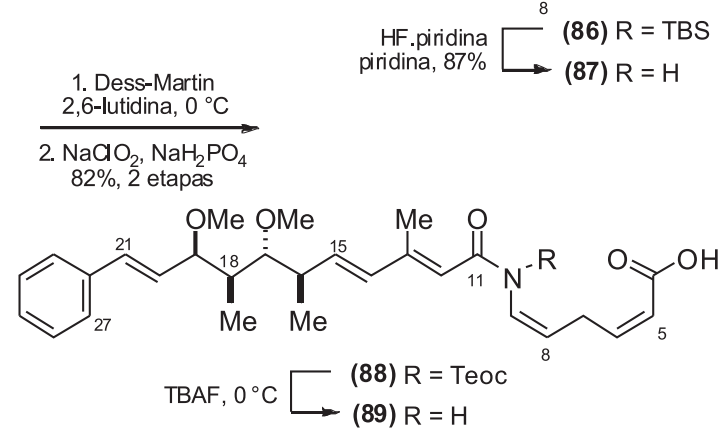

$\mathrm{NaH}_{2} \mathrm{PO}_{4}$ $(\mathrm{PhO})_{2} \mathrm{P}(\mathrm{O}) \mathrm{N}_{3}$

$\underset{23 \%, 2 \text { etapas }}{\stackrel{\mathrm{MeO}_{2} \mathrm{CCH}_{2} \mathrm{NH}_{2} \cdot \mathrm{HCl}(54)}{\longrightarrow}}(+)-$ Crocacina A (1) 


\section{Síntese de Chakraborty e colaboradores ${ }^{7}$}

A segunda síntese total da crocacina A (1) também foi relatada em 2003 por Chakraborty e Laxman. ${ }^{7}$ A análise retrossintética mostra que a dupla ligação (Z)-8,9-enamida pode ser construída a partir de reação de eliminação de Peterson de um $\beta$-hidroxi silano na etapa final (Esquema 30). $O$ intermediário $\alpha$-azido- $\beta$-hidroxialquilsilano 90 poderia ser gerado após abertura regiosseletiva com íon azida do sililepóxido 91. Este sililepóxido seria obtido a partir de um precursor (Z)-5,6-enoicoamida, construído por redução parcial estereosseletiva do 1,4-diino $\mathbf{9 2}$.

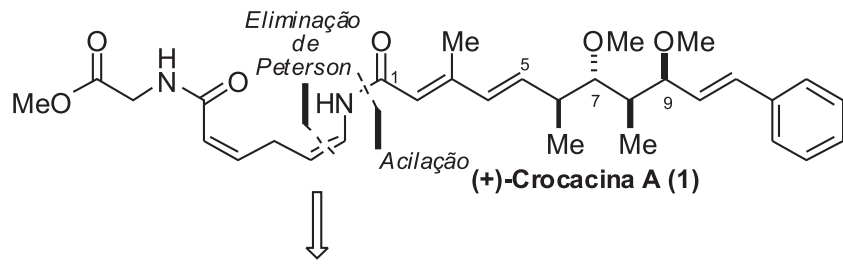

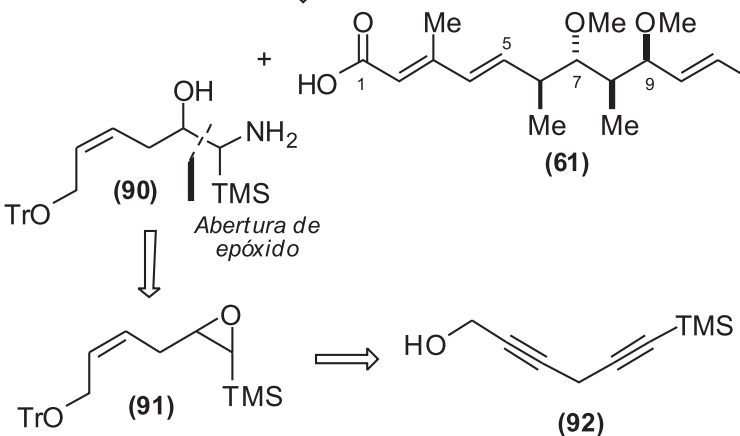

Esquema 30. Planejamento retrossintético de Chakraborty para obtenção da crocacina $A(4)^{\top}$

A síntese foi iniciada a partir do álcool propargílico (82), o qual foi transformado no derivado acetilênico sililado 93 (84\%, 2 etapas) via formação do diânion acetilídeo, o qual é posteriormente sililado na presença de TMSCl para fornecer 93 (Esquema 31). A hidroxila primária em $\mathbf{9 3}$ foi funcionalizada para tosilato (93\%) o qual foi acoplado a outra subunidade do alcino $\mathbf{8 2}$ via uma reação mediada por $\mathrm{Cu}(\mathrm{I})^{62,65}$ levando ao 1,4-diino 92 em $76 \%$ de rendimento. Redução parcial estereosseletiva de 92 usando P-2 Ni ${ }^{63,65}$ levou à formação do dieno 94 (53\%). Nesta condição também foi observada a redução completa da extremidade do término álcool propargílico. A epoxidação do vinilsilano foi realizada com sucesso após promover o aumento do impedimento estéreo e a diminuição da contribuição eletrônica da hidroxila alílica em 94. Para isto a hidroxila em 94 foi protegida com $\operatorname{TrCl}(82 \%)$ e a sililvinil olefina
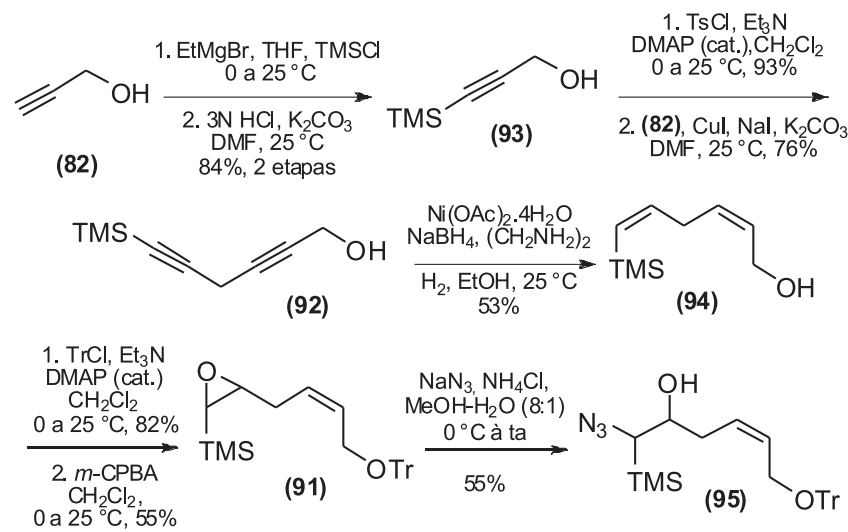

Esquema 31. Obtenção do $\alpha$-azido- $\beta$-hidroxialquilsilano 90 foi epoxidada com $m$-CPBA fornecendo 91 em $55 \%$ de rendimento (os subprodutos incluem o diepóxido e o outro epóxido). O epóxido 91 foi aberto regiosseletivamente no centro sililsubstituído após tratamento com $\mathrm{NaN}_{3}$ na presença de $\mathrm{NH}_{4} \mathrm{Cl}$ para fornecer o $\alpha$ azido- $\beta$-hidroxialquilsilano $95 \mathrm{em} 55 \%$ de rendimento. ${ }^{57}$

O grupo azida em $\mathbf{9 5}$ foi seletivamente reduzido para amina na presença de $\mathrm{LiAlH}_{4}$ e o produto resultante $\mathbf{9 0}$ acoplado diretamente com o ácido 61 preparado na síntese da crocacina $\mathrm{C}^{4}$ (Esquema 32). Esta reação foi promovida pelo tratamento de $61 \mathrm{com}$ hidrocloreto de $N$-hidroxisuccinimida usando 1-etil-3-(3-dimetilaminopropil)carbodiimida (EDCI) na presença de quantidades catalíticas de DMAP. Nestas condições a amida 96 foi obtida em 62\% de rendimento a partir de $\mathbf{9 5}$.

Seqüência de proteção e desproteção seletiva forneceu o álcool (Z)-alílico 97 em 68\% de rendimento para duas etapas. Oxidação em duas etapas (74\%) seguida por reação do ácido resultante com o éster metílico da glicina (54) forneceu o intermediário avançado $99(93 \%)$ (Esquema 32).

Finalmente, desproteção da hidroxila com -TBS utilizando TBAF forneceu o intermediário oxiânion que realizou uma reação de eliminação de Peterson in situ, permitindo a instalação da função cis enamida com completa estereosseletividade em $86 \%$ de

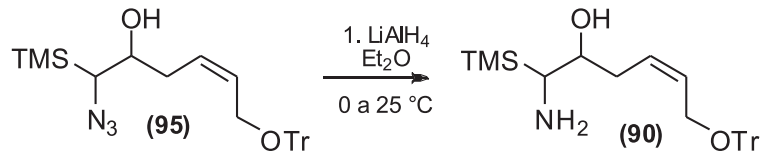

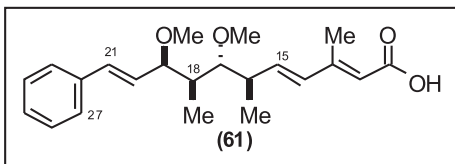

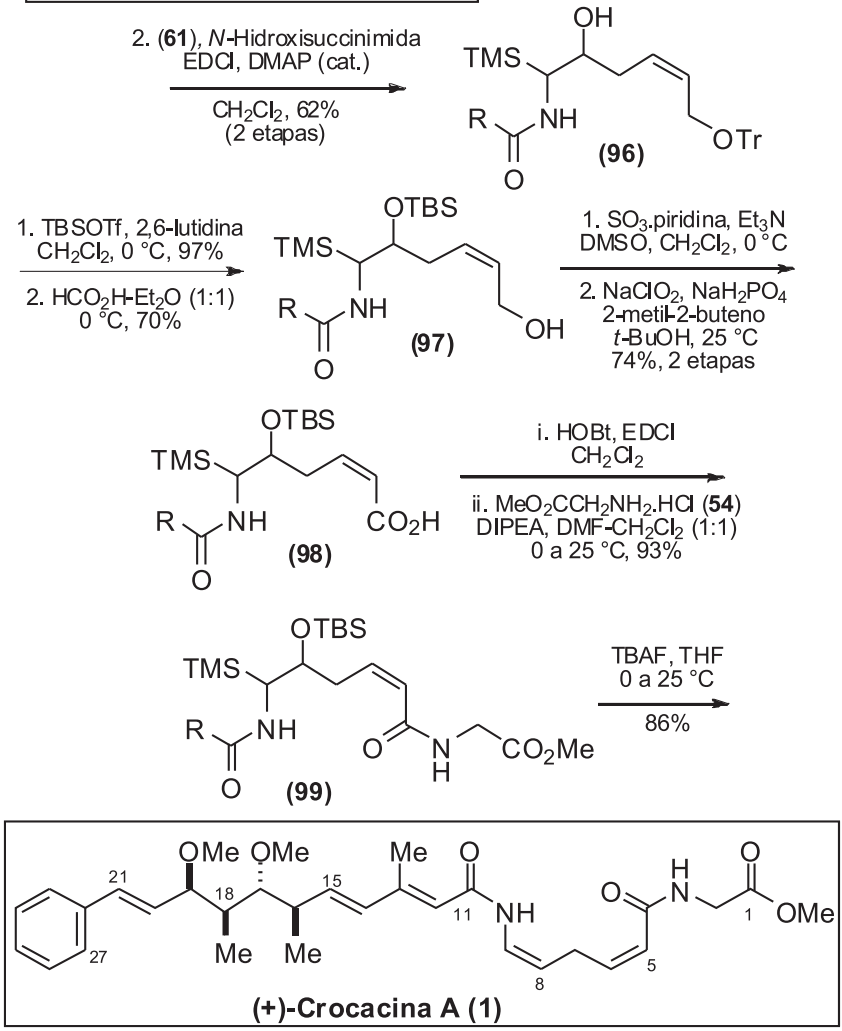

EDCl: hidrocloreto de 1-(3-dimetilaminopropil)-3-etilcarbodiimida

Esquema 32. Síntese total da (+)-crocacina A (1) por Chakraborty e colaboradores $^{7}$ 
rendimento, resultando em uma aproximação muito bem sucedida para completar a síntese total da (+)-crocacina A (1) (Esquema 32). A estratégia explorada por Chakraborty permitiu a obtenção da crocacina A em 23 etapas a partir da $\mathrm{N}$-aciloxazolidinationa 19 e $2,4 \%$ de rendimento global. ${ }^{7}$

\section{SÍNTESES FORMAIS DAS CROCACINAS}

\section{Síntese do intermediário comum 14 por Gurjar e colaboradores ${ }^{11}$}

Em 2003, Gurjar e colaboradores ${ }^{11}$ desenvolveram uma alternativa sintética baseada na transformação de carboidratos para chegar ao fragmento 14 (Esquema 3) comum às sínteses relatadas para as crocacinas. Nesta aproximação, os centros quirais da $D$-glicose foram transformados para produzir 14 estereosseletivamente.

A seqüência desenvolvida parte da 1,2:5,6-Di- $O$-cicloexilideno$D$-glucofuranose $\mathbf{1 0 0}^{66}$ (Esquema 33 ), a qual foi submetida às reações sucessivas de oxidação $(78 \%)$, Wittig $(67 \%)$ e redução catalítica da dupla resultante $(97 \%)$, fornecendo o derivado 3-Cmetil-3-deoxi 101. Tratamento de 101 com $\mathrm{H}_{2} \mathrm{SO}_{4}$ em $\mathrm{MeOH}$, seguido de mesilação e refluxo com $\mathrm{NaI}$ em butanona, conduz à olefina 102 em bons rendimentos. A conversão de $\mathbf{1 0 2}$ para o derivado 5,6eno 103 foi realizada utilizando condições padrão da reação de Heck, ${ }^{67,68}$ fornecendo o derivado trans-estireno 103 (63\%), o qual foi tratado com Amberlyst IR120 em MeOH, conduzindo ao metilfuranosídeo intermediário, no qual a hidroxila em $\mathrm{C} 2$ foi metilada utilizando $\mathrm{NaH}$ e MeI para fornecer 104 em $78 \%$ de rendimento para a seqüência de 2 etapas.

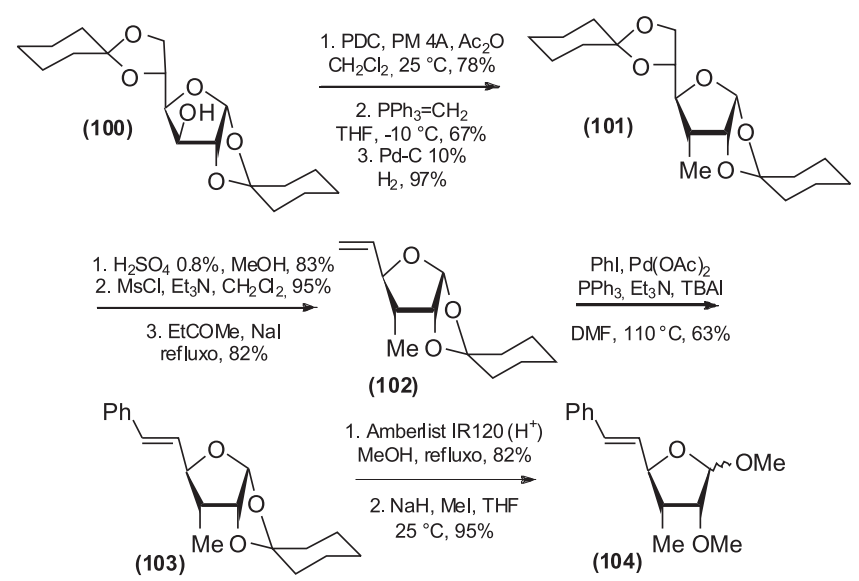

Esquema 33. Obtenção do metilfuranosídeo 104

Hidrólise do furanosídeo 104 (Esquema 34) resultou na formação de $\mathbf{1 0 5}$ (79\%), que foi tratado com $\mathrm{MeMgCl}$ em THF, fornecendo o diol acíclico (79\%). A hidroxila no carbono correspondente a C6 (em 3) foi protegida com o grupo TBS fornecendo o álcool $106(86 \%)$. A hidroxila secundária livre em C9 passou por uma reação de inversão de Mitsunobu (66\%) seguida por hidrólise com $\mathrm{LiOH}$ em MeOH conduzindo ao composto 107 (62\%). A hidroxila em C9 foi metilada (96\%) e após a sequiência de desproteção, oxidação (resultando em 108) e reação de Wittig, uma reação de hidroboração-oxidação ${ }^{69}$ régio- e diastereosseletiva de 109 promoveu a formação exclusiva do intermediário $14 \mathrm{em}$ bons rendimentos (Esquema 34).

Apesar de a rota apresentada ser bastante extensa (19 etapas a partir da D-glucofuranose 100), ela parte de matéria-prima abundante e acessível e fornece o intermediário $\mathbf{1 4}$ para a síntese das
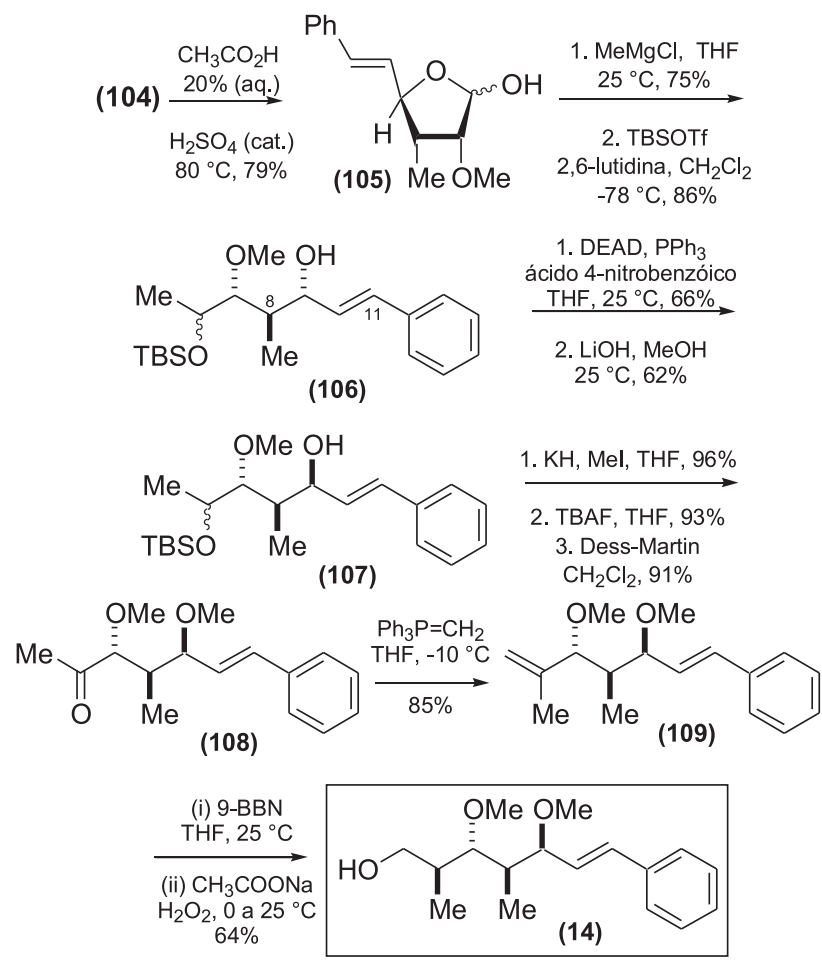

Esquema 34. Obtenção do fragmento 14 comum às rotas sintéticas

crocacinas de maneira enantiosseletiva. Um outro diferencial é a obtenção do fragmento acíclico a partir de um substrato de partida cíclico.

\section{Síntese do enantiômero do intermediário comum 14 por Raghavan e colaboradores ${ }^{12}$}

Nesta aproximação desenvolvida em 2004 pelo grupo de Raghavan, ${ }^{12}$ foi realizada a síntese do enantiômero de 14. O grupo explora uma reação de heterofuncionalização de alceno mediada por trifluoracetato de mercúrio via participação intramolecular de um grupo sulfinil.

A rota inicia-se a partir da reação de adição de Michael do tiofenol à oxazolidinona $\mathbf{1 1 0}^{70}$ promovida por tetracloreto de titânio, fornecendo o sulfeto 111 em $88 \%$ de rendimento e $84 \%$ de diastereosseletividade (Esquema 35). ${ }^{71}$ Clivagem redutiva do auxiliar quiral, seguida por oxidação de $\operatorname{Swern}^{42}$ do álcool resultante e reação de Wittig forneceu exclusivamente o éster $(E)$ - $\alpha, \beta$-insaturado $\mathbf{1 1 2}$ em $85 \%$ de rendimento (2 etapas). Oxidação do sulfeto $\mathbf{1 1 2}$
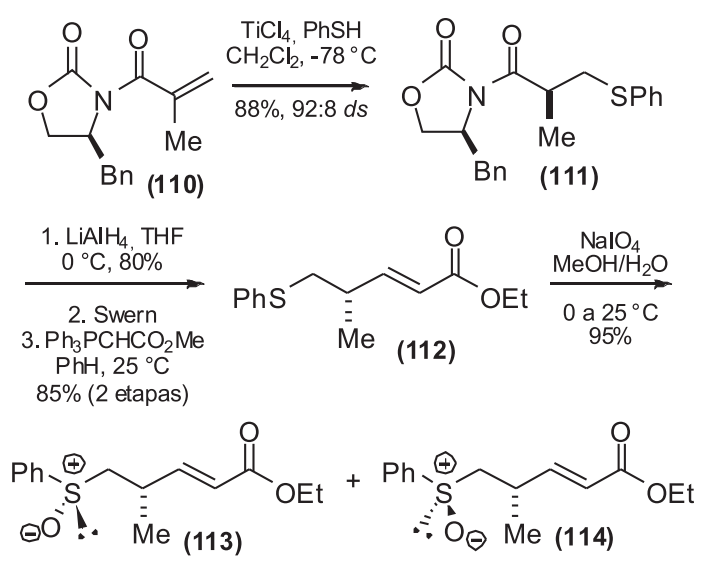

Esquema 35. Obtenção dos sulfóxidos diastereoisoméricos 113 e 114 
com $\mathrm{NaIO}_{4}{ }^{72}$ forneceu uma mistura equimolar e inseparável dos sulfóxidos 113 e $\mathbf{1 1 4}$ em $85 \%$ de rendimento.

Tratamento da mistura de sulfóxidos insaturados com trifluoracetato de mercúrio em água:tolueno forneceu os hidroxiésteres 115 e 116 (75\%, 18:1 ed) após demercuração dos organomercúrios formados (III e IV) com $\mathrm{NaBH}_{4}$ (Esquema 36). ${ }^{73}$ A régio- e diastereosseletividade observada na reação com mercúrio pode ser atribuída à formação dos sulfoxônios intermediários I e II pelo ataque nucleofílico dos grupos sulfinila às olefinas complexadas ao íon mercurínio. Subseqüente hidrólise (resultante do ataque da água ao enxofre $)^{74}$ fornece os organomercúrio intermediários III e IV, os quais após demercuração conduzem aos produtos 115 e 116. A indução assimétrica é influenciada pelos substituintes de forma a minimizar interação alílica $A^{1,3} \mathrm{e}$ a configuração no sulfóxido não exerce nenhuma influência sobre a estereoquímica resultante.

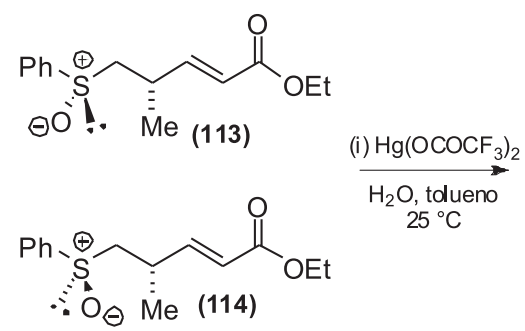

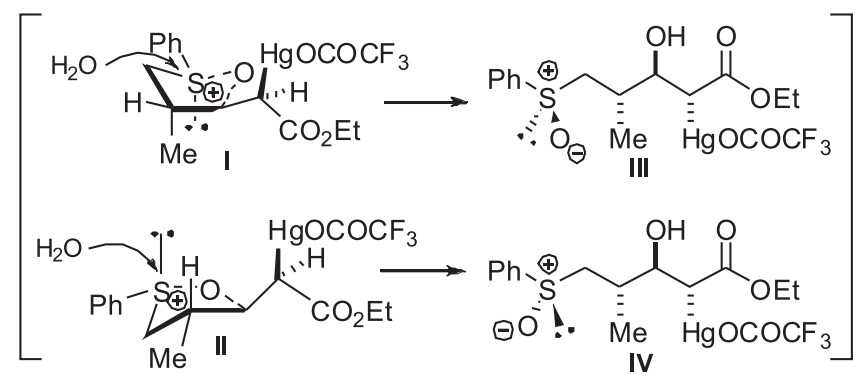

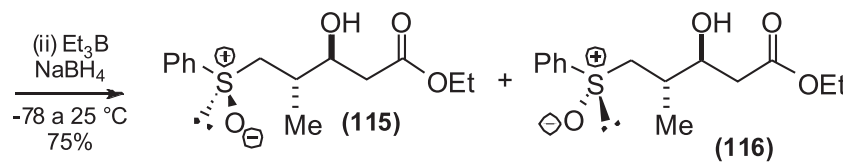<smiles>CCOC(=O)[C@H](C)[C@H](O)[C@H](C)[C@H](C)CSc1ccccc1</smiles>

(ii) Mel, HMPA, $75 \%$

(117)

Esquema 36. Obtenção do sulfeto 117

O grupo metila em C8 (numeração de 3 ) foi introduzido via uma reação de alquilação de Frater (Esquema 36). ${ }^{75}$ Para evitar alquilação em C5, o grupo sulfinila em 115 e 116 foi reduzido a sulfeto por tratamento com $\mathrm{TiCl}_{3}{ }^{76}(85 \%)$ e o produto resultante, tratado com LDA levando à formação do diânion que, após adição de MeI, forneceu 117, juntamente com o diastereoisômero em uma proporção de 4:1 (75\%).

Hidrólise de $\mathbf{1 1 7}$ seguida por tratamento com morfolina promoveu a formação da amida 118 (63\%, 2 etapas), que foi tratada com o ânion de lítio gerado a partir da vinilestanana 119 fornecendo a cetona insaturada 120 em $80 \%$ de rendimento (Esquema 37). Redução da carbonila dirigida pelo grupo hidroxila forneceu o diol 1,3-anti ${ }^{77}$ (85\%), no qual as hidroxilas foram metiladas para conduzir ao dimetiléter 121 (80\%). Nova oxidação do sulfeto forneceu novamente a mistura de sulfóxidos $\mathbf{1 2 2}$ (80\%), que foram tratados com anidrido
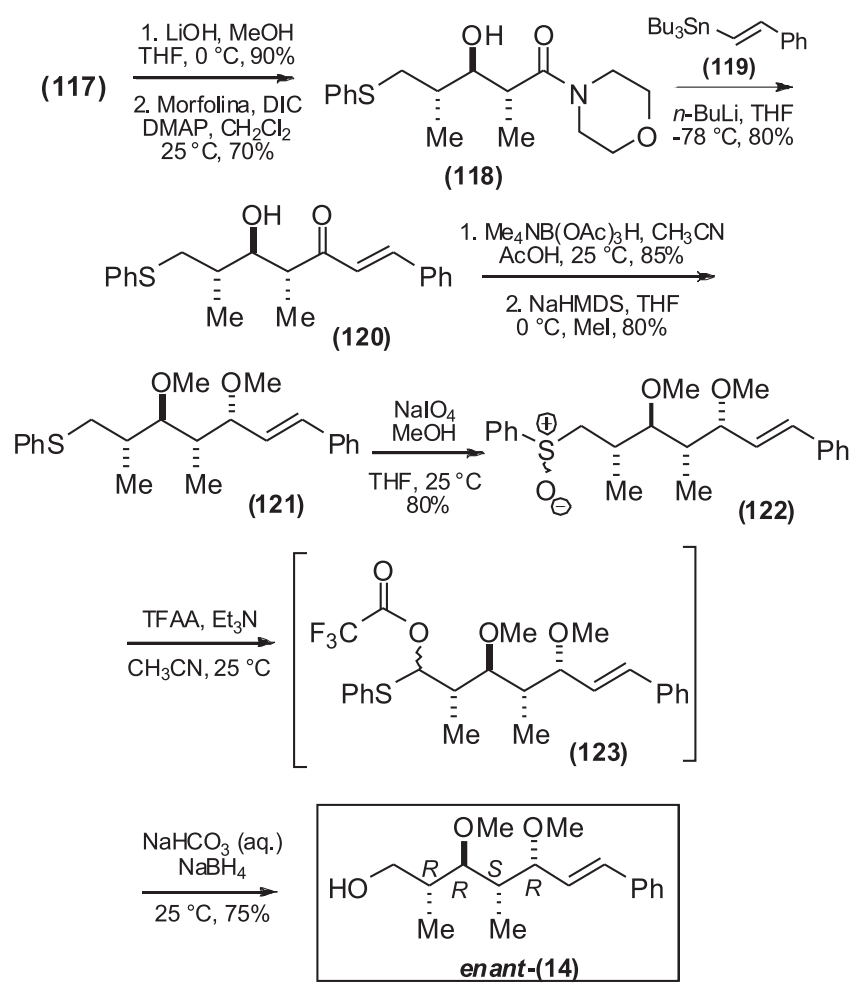

Esquema 37. Obtenção do álcool enant-14

trifluoracético (TFAA) e $\mathrm{Et}_{3} \mathrm{~N}$ e após rearranjo de Pummerer ${ }^{78}$ forneceram o intermediário $\mathbf{1 2 3}$, o qual sem ser isolado foi submetido à hidrólise, promovendo a formação do álcool enant-14.

Síntese formal das crocacinas por Fürstner e colaboradores ${ }^{13}$

Em 2005, Fürstner e colaboradores ${ }^{13}$ relataram a síntese do fragmento policetídico 61 e do derivado correspondente ao éster $t$ butílico, os quais podem ser convertidos aos compostos da família das crocacinas. As estratégias utilizadas envolvem a aplicação de uma reação aldólica syn-seletiva mediada por titânio e controlada por um auxiliar derivado do valinol, uma reação de adição antiseletiva catalisada por Pd e mediada por zinco de um mesilato propargílico ao aldeído quiral derivado do álcool 35 (Esquema 11) e a utilização comparativa das condições de Stille e Suzuki para a reação de acoplamento cruzado para a instalação do dieno.

Os autores optaram por realizar a reação aldólica utilizando o éster 125 contendo um auxiliar quiral derivado do valinol, ${ }^{79} \mathrm{o}$ qual pode ser preparado a partir de $\mathbf{1 2 4}$ (em $82 \%$ de rendimento) por adição sucessiva de cloreto de tosila e cloreto de propanoila na presença de excesso de trietilamina (Esquema 38). Reação aldólica mediada por titânio entre $\mathbf{1 2 5}$ e o cinamaldeído (9) forneceu o produto aldólico 126 em $85 \%$ de rendimento e 10:1 de diastereosseletividade. Após proteção da hidroxila secundária em 126 (-OTBS), o auxiliar foi removido por clivagem redutiva na presença de $\mathrm{LiBH}_{4}$ (89\%) e o álcool resultante oxidado pela periodinana de Dess-Martin para fornecer o aldeído $\mathbf{1 2 7}$ em $87 \%$ de rendimento.

Reação de adição do mesilato 128 ao aldeído 127 na presença de $\mathrm{Et}_{2} \mathrm{Zn}$ e quantidades catalíticas de $\mathrm{Pd}(\mathrm{OAc})_{2}$ e $\mathrm{PPh}_{3}$, de acordo com o procedimento descrito por Marshall, ${ }^{80}$ promoveu a formação do alcino $129(72 \%$, ed > 12:1) com alta seletividade anti e excelente nível de controle do reagente (Esquema 38). O alcino resultante foi imediatamente tratado com TBAF em THF para desproteção da hidroxila secundária $(88 \%)$ e as hidroxilas no diol resultante foram metiladas na presença de triflato de metila (MeOTf) 


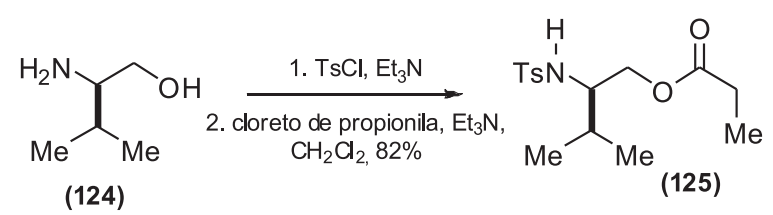<smiles>[R]C(/C=C/c1ccccc1)C(C)C(=O)OC[C@H]([NH3+])C(C)C</smiles>

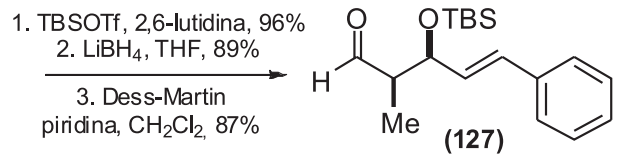

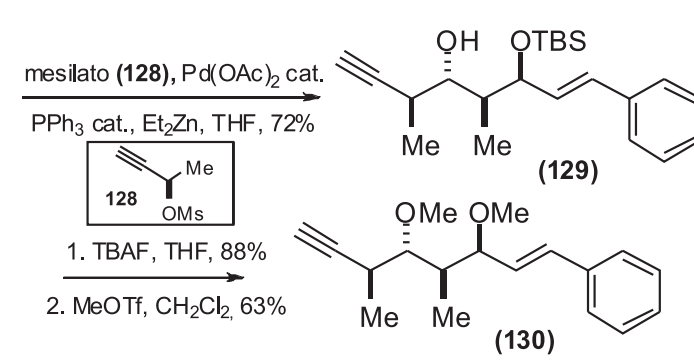

Esquema 38. Obtenção do alcino 130

e 2,6-di-t-butil-metilpiridina para fornecer o alcino $\mathbf{1 3 0}$ em $63 \%$ de rendimento.

Os iodetos 133a e 133b (Esquema 39) foram selecionados para participar da reação de acoplamento cruzado e formação do éster $\alpha, \beta, \gamma, \delta$-insaturado no produto final. A síntese dos iodetos baseiase na adição estereosseletiva de estanilcuprato ${ }^{81}$ ao alquinoato $\mathbf{1 3 1}$ seguido por troca Sn-I em 132 com retenção da estereoquímica da dupla ligação.

$$
\begin{aligned}
& \mathrm{Me}=\operatorname{COOR} \stackrel{\left(\mathrm{Bu}_{3} \mathrm{Sn}\right)(\mathrm{Bu}) \mathrm{Cu}(\mathrm{CN}) \mathrm{Li}_{2}}{\longrightarrow} \mathrm{Bu}_{3} \mathrm{Sn} \underset{\mathrm{Me}}{\longrightarrow} \prod_{\mathrm{O}} \mathrm{OR} \\
& \text { (131b) } \mathrm{R}=t-\mathrm{Bu} \\
& \stackrel{\mathrm{I}_{2}, \mathrm{CH}_{2} \mathrm{Cl}_{2}}{\longrightarrow} \mathrm{Me}_{\mathrm{O}}^{\mathrm{OR}} \\
& \text { (133a) } \mathrm{R}=\left(\mathrm{CH}_{2}\right)_{2} \mathrm{SiMe}_{3} \\
& \text { (133b) } \mathrm{R}=t \text {-Bu }
\end{aligned}
$$

Esquema 39. Obtenção dos iodetos vinílicos 133a e $\mathbf{1 3 3 b}$

Para promover as reações de acoplamento cruzado, o alcino $\mathbf{1 3 0}$ foi hidroestanilado na presença de $\mathrm{Bu}_{3} \mathrm{SnH}$ e quantidades catalíticas de $\mathrm{PdCl}_{2}\left(\mathrm{PPh}_{3}\right)$ formando a alquenilestanana $7 \mathrm{em} 88 \%$ de rendimento. Foram realizadas várias tentativas de acoplamento entre os fragmentos utilizando variações da condição de Stille, entretanto o produto de acoplamento desejado foi obtido apenas em baixos rendimentos (30-40\%). Em uma tentativa de remediar este problema, os autores exploraram como alternativa utilizar as condições de Suzuki, fazendo-se a hidroboração de $\mathbf{1 3 0}$ com bis(siamil)borana ((Sia) $\left.{ }_{2} \mathrm{BH}\right)$ seguida por reação catalisada por paládio com os iodetos vinílicos 133a a $\mathbf{1 3 3 b}$, o que permitiu a obtenção de $\mathbf{1 3 5 b}$ em rendimentos satisfatórios (79\%). Finalmente, tratamento de $\mathbf{1 3 5 a}$ com TBAF em THF promove a formação do ácido carboxílico $\mathbf{6 1}$ em $89 \%$ de rendimento. Esta via sintética possibilitou a preparação de um intermediário viável para a aplicação na síntese dos membros da família das crocacinas e utiliza 9 etapas na seqüência linear mais longa.

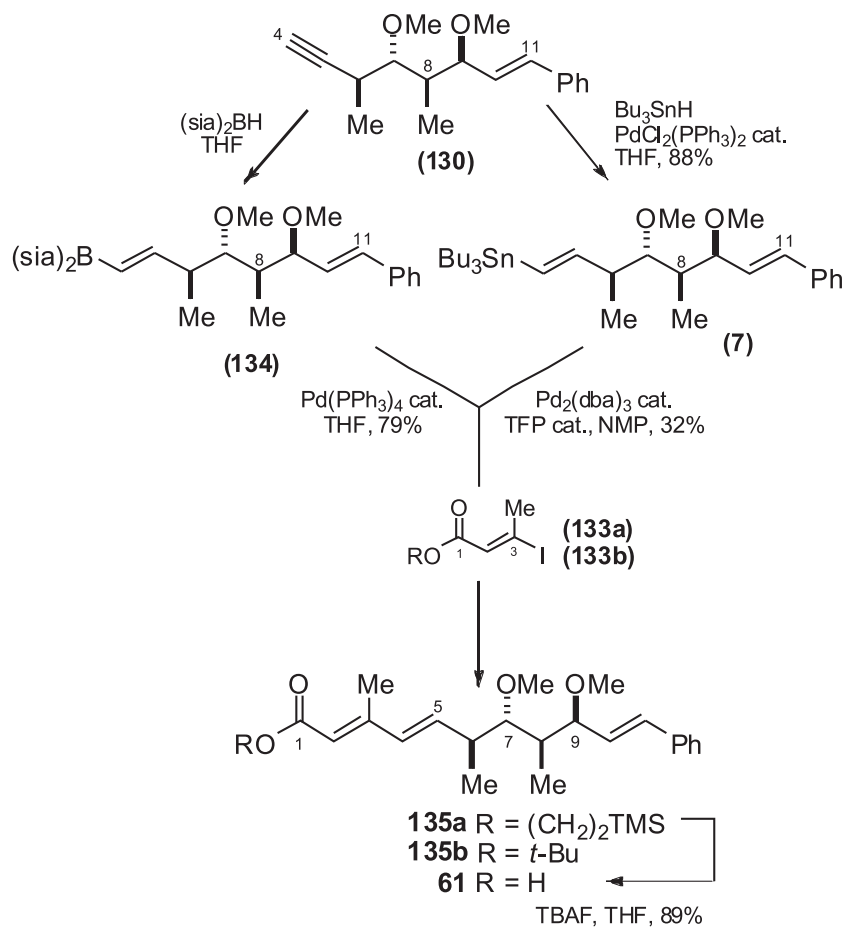

Esquema 40. Obtenção dos trienoatos 61 e $135 b$

Síntese formal das crocacinas por Yadav e colaboradores ${ }^{14}$

Em 2007, Yadav e colaboradores ${ }^{14}$ relataram a síntese formal da crocacina $\mathrm{C}$ explorando reações de hidroboração assimétrica, metátese cruzada e reação de olefinação de Julia modificada para a obtenção do trienoato linear 26 (Esquema 9).

A síntese inicia-se com a metanólise catalisada por ácido da lactona bicíclica 136 para fornecer o éster 137 em 80\% de rendimento (Esquema 41). Redução do éster para álcool primário na

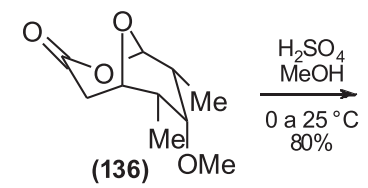<smiles></smiles>

$$
\begin{gathered}
\text { 1. } \mathrm{LiAlH}_{4} \mathrm{THF}, 0 \text { a } 25^{\circ} \mathrm{C} \\
\text { 2. } \mathrm{I}_{2} \mathrm{Ph}_{3} \mathrm{P}, \text { Imidazol } \\
\mathrm{CH}_{3} \mathrm{CN} / \mathrm{Et} \mathrm{t}_{2} \mathrm{O}(1: 3) 0{ }^{\circ} \mathrm{C}, 85 \% \\
\hline \text { 3. } \mathrm{t} \text {-BuOK, THF, } 0{ }^{\circ} \mathrm{C}, 83 \%
\end{gathered}
$$

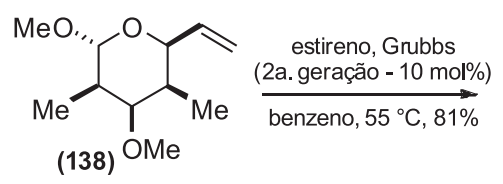

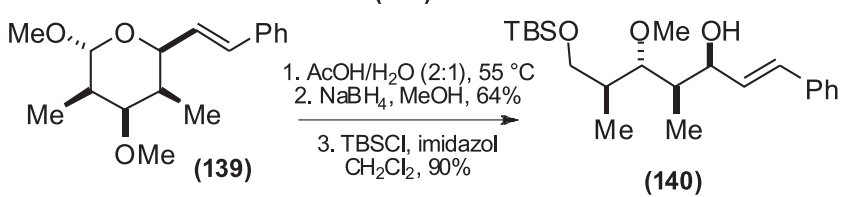<smiles>COC(/C=C/c1ccccc1)C(C)C(OC)C(C)CO</smiles>

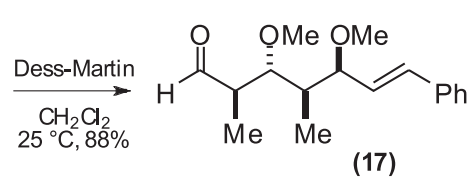

(17) 
presença de $\mathrm{LiAlH}_{4}$, seguida por formação do iodeto e subseqüente eliminação catalisada por base resultou na formação da olefina 138. A olefina 138 foi utilizada em uma reação de metátese cruzada de olefinas com estireno na presença de catalisador de Grubbs de $2^{\mathrm{a}}$ geração $(10 \mathrm{~mol} \% \text { em benzeno })^{82}$ para fornecer o derivado transestireno 139 em $81 \%$ de rendimento ( $E: Z$ 98:2). Hidrólise ácida do éter-lactol 139 seguida por redução mediada por $\mathrm{NaBH}_{4}$ resultou na formação do 1,5-diol (64\% de rendimento) no qual a hidroxila primária foi seletivamente protegida na presença de $\mathrm{TBSCl}$ e imidazol para fornecer 140 (90\%). A hidroxila secundária foi metilada (94\%) e após dessililação (90\%), o álcool primário 14, comum às outras rotas, foi oxidado com Dess-Martin para fornecer o aldeído 17 em $88 \%$ de rendimento.

A sulfona 144 necessária para o acoplamento de Julia foi sintetizada a partir do mercaptobenzotriazol (MBT) 141 (Esquema 42). Tratamento de $\mathbf{1 4 1}$ com cloroacetona na presença de trietilamina forneceu a cetona 142 (97\%) que participou de uma reação de Wittig com ilídeo estabilizado $\left(\mathrm{Ph}_{3} \mathrm{P}=\mathrm{CHCO}_{2} \mathrm{Et}\right)$ fornecendo o éster $\alpha, \beta$ insaturado 143 (68\%), no qual o sulfeto foi oxidado com Oxone ${ }^{\circledR}$ resultando na formação de 144 (93\%).

Os fragmentos 17 e $\mathbf{1 4 4}$ foram acoplados via reação de olefinação de Julia modificada, na qual a sulfona pré-litiada reagiu com o aldeído 17 para fornecer o trienoato 26 (56\%), intermediário conhecido nas rotas para síntese total das crocacinas. ${ }^{4}$<smiles>Sc1nc2ccccc2s1</smiles>

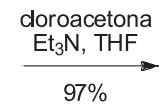

(141)

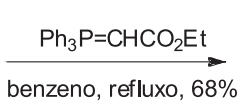<smiles>CCOC(=O)/C=C(\C)CSc1nc2ccccc2s1</smiles>

(143)

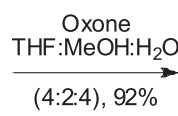<smiles>CCOC(=O)/C=C(\C)CS(=O)(=O)c1nc2ccccc2s1</smiles>

(144)

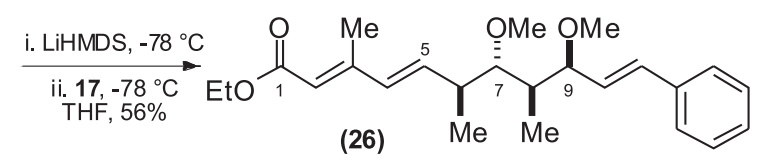

Esquema 42. Síntese formal das crocacinas por Yadav e colaboradores

\section{Segunda síntese formal das crocacinas por Yadav e colaboradores ${ }^{15}$}

Também em 2007 Yadav ${ }^{15}$ publicou uma segunda rota para a síntese formal estereosseletiva das crocacinas via reação de ciclização de Prins (Esquemas 43 e 44). A ciclização de Prins tem se tornado uma ferramenta sintética poderosa para a construção de tetraidropiranos polissubstituídos e sido amplamente aplicada na síntese de produtos naturais. ${ }^{83}$

A síntese inicia-se com a reação de ciclização de Prins entre o álcool homoalílico 145 (preparado a partir do éter $(S)$-benzilglicidílico ${ }^{84}$ e o aldeído $\mathbf{1 4 6}^{85}$ na presença de TFA, a qual resultou no pirano tetrassubstituído 147 (55\% de rendimento) após hidrólise do trifluoracetato resultante com $\mathrm{K}_{2} \mathrm{CO}_{3} \mathrm{em} \mathrm{MeOH}$ (Esquema 43). A hidroxila primária em 147 foi seletivamente protegida na presença de TBSCl e imidazol (86\%) e a hidroxila secundária metilada (MeI, NaH) para fornecer o composto 148 (90\%). Debenzilação de 148 sob condição de Birch forneceu o álcool primário correspondente (88\%), no qual a hidroxila foi protegida na presença de $\mathrm{MOMCl}$ e DIPEA para fornecer 149 em $94 \%$ de rendimento.
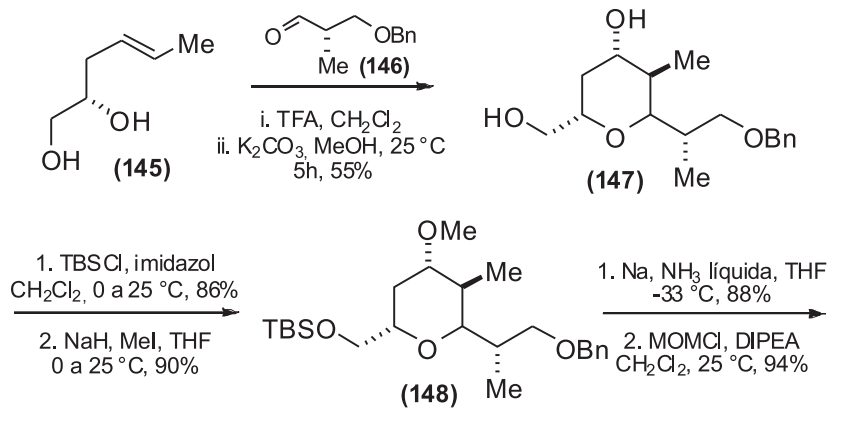

(149) $\begin{aligned} & \mathrm{Me} \\ & \mathrm{MeMOM}\end{aligned}$
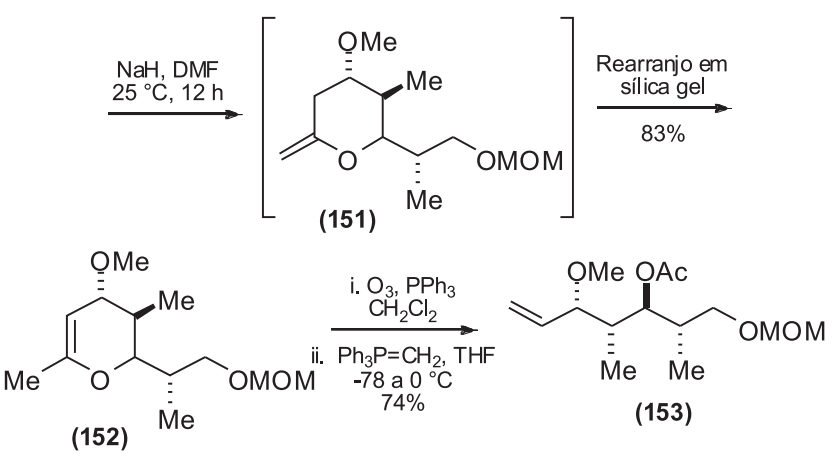

Esquema 43. Obtenção do intermediário acíclico 153

Clivagem do éter de silício (TBAF, 94\%) seguida por tratamento do álcool resultante com trifenilfosfina, $\mathrm{I}_{2}$ e imidazol em benzeno levou ao iodeto $\mathbf{1 5 0}$ em $95 \%$ de rendimento, no qual foi promovida a eliminação de $\mathrm{HI}^{86}$ utilizando $\mathrm{NaH}$ em DMF, produzindo a olefina exo-enólica 151 que sofreu rearranjo para formar a olefina endo-152 em $83 \%$ de rendimento após coluna cromatográfica. O substrato $\mathbf{1 5 2}$ foi então submetido à reação de ozonólise para fornecer o acetoxialdeído intermediário, que foi tratado sem purificação prévia com trifenilfosforana resultando no produto acíclico 153 (74\%).

Hidrólise de 153 na presença de $\mathrm{K}_{2} \mathrm{CO}_{3}$ em metanol (96\%) se-
(153)

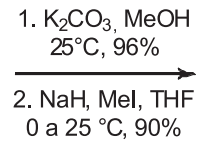<smiles>C=C[C@H](OC)[C@@H](C)C(OC)C(C)COC</smiles><smiles>COCC(C)C(OC)[C@H](C)[C@H](/C=C/c1ccccc1)OC</smiles>

(155)

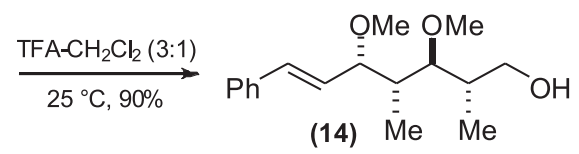<smiles>CCOC(=O)C=C(C)C=CC(C)C(OC)C(C)[C@H](C)C(C=Cc1ccccc1)OC</smiles>

Esquema 44. Obtenção do trienoato 26 
guido por metilação da hidroxila secundária resultante forneceu dimetil éter 154 em $90 \%$ de rendimento (Esquema 44). A etapa seguinte envolveu uma reação de metátese cruzada de olefinas utilizando catalisador de Grubbs de $2^{\mathrm{a}}$ geração ${ }^{82,87}$ (condição a) que possibilitou a obtenção de $\mathbf{1 5 5}$ em $92 \%$ de rendimento. Alternativamente, foi testada a reação nas condições de acoplamento de $\mathrm{Heck}^{88}$ (condição b) entre 154 e iodobenzeno na presença de $\mathrm{Pd}(\mathrm{OAc})_{2}, \mathrm{PPh}_{3}$ e $\mathrm{Et}_{3} \mathrm{~N}$ em DMF promovendo a formação de $\mathbf{1 5 5}$ em $65 \%$ de rendimento. Remoção do grupo protetor MOM (90\%) no intermediário 155 forneceu o álcool 14, comum às demais sínteses. ${ }^{3-10}$ As etapas finais envolvem a oxidação de $\mathbf{1 4}$ com DessMartin e reação de olefinação de Julia modificada com 144 para obtenção do trienoato $\mathbf{2 6}$ conforme descrito anteriormente, ${ }^{14} \mathrm{em}$ $50 \%$ de rendimento para as duas etapas.

\section{CONCLUSÕES}

Nesta revisão foram apresentadas as principais abordagens sintéticas que promoveram as sínteses totais de antibióticos complexos do grupo das crocacinas. As sínteses relatadas apresentam de forma sucinta as diversas estratégias utilizadas na construção dos sistemas polipropionatos, duplas ligações conjugadas e instalação de funcionalidades do tipo enamidas com geometria $Z$ entre outras reações. É possível perceber o imenso potencial que a síntese orgânica oferece para a construção de moléculas complexas e destacamos também a possibilidade de idealização e desenvolvimento no Brasil da síntese total e competitiva de moléculas complexas.

\section{AGRADECIMENTOS}

À Fundação de Amparo à Pesquisa do Estado de São Paulo (FAPESP) e ao Conselho Nacional para o Desenvolvimento Científico e Tecnológico (CNPq) pelo apoio financeiro. Os autores cumprimentam a todos que lutaram em prol do fortalecimento da Sociedade Brasileira de Química e das publicações Química Nova e Journal of the Brazilian Chemical Society nestes 30 anos; a Profa. Helena Ferraz incontestavelmente faz parte deste grupo. Gostaríamos de agradecer especialmente ao Prof. G. L. Barron (University of Guelph) que cordialmente nos permitiu o uso da fotografia de "Chondromyces crocatus - the bacterium that wanted to be a fungus!" nesta publicação.

\section{REFERÊNCIAS E NOTAS}

1. Jansen, R.; Washausen, P.; Kunze, B.; Reichenbach, H.; Höfle, G.; Eur. J. Org. Chem. 1999, 1085; Kunze, B.; Jansen, R.; Höfle, G; Reichenbach, H.; J. Antibiot. 1994, 47, 881.

2. A numeração adotada para os átomos segue a originalmente utilizada por Jansen e colaboradores na referência 1 .

3. Feutrill, J. T.; Lilly, M. J.; Rizzacasa, M. A.; Org. Lett. 2000, 2, 3365.

4. Chakraborty, T. K.; Jayaprakash, S.; Tetrahedron Lett. 2001, 42, 497; Chakraborty, T. K.; Jayaprakash, S.; Laxman, P.; Tetrahedron 2001, 46, 9461.

5. Dias, L. C.; de Oliveira, L. G.; Org. Lett. 2001, 3, 3951.

6. Feutrill, J. T.; Rizzacasa, M. A.; Aust. J. Chem. 2003, 56, 783.

7. Chakraborty, T. K., Laxman, P.; Tetrahedron Lett. 2003, 44, 4989.

8. Feutrill, J. T.; Lilly, M. J.; Rizzacasa, M. A.; Org. Lett. 2002, 4, 525.

9. Chakraborty, T. K.; Laxman, P.; Tetrahedron Lett. 2002, 43, 2645.

10. Dias, L. C.; de Oliveira, L. G.; Vilcachagua, J. D.; Nigsch, F.; J. Org. Chem. 2005, 70, 2225; Dias, L. C.; de Oliveira, L. G.; Meira, P. R. R.; Pure Appl. Chem. 2007, 79, 163.

11. Gurjar, M. K.; Khaladkar, T. P.; Borhade, R. G.; Murugan, A.; Tetrahedron Lett. 2003, 44, 5183.

12. Raghavan, S.; Reddy, R.; Tetrahedron Lett. 2004, 45, 5593.

13. Basev, M.; Brehm. C.; Fürstner, A.; Coll. Czech. Chem. Commun. 2005, 70, 1696.

14. Yadav, J. S.; Reddy, P. V.; Chandraiah, L.; Tetrahedron Lett. 2007, 48, 145.
15. Yadav, J. S.; Reddy, M. S.; Rao, P. P.; Prasad, A. R.; Synlett 2007, 2049.

16. Os cálculos foram realizados com a estrutura de $\mathbf{3}$, que representa o elemento estrutural relevante para a atribuição da estereoquímica relativa. Para as buscas conformacionais, o HyperChem (versão 5.1) foi equipado com o módulo ChemPlus (versão 2.0).

17. Para uma discussão sobre centros quirais e estereogênicos ver: Fujita, S.; Tetrahedron 2004, 60, 11629; Fujita, S.; J. Org. Chem. 2004, 69, 3158.

18. Crowley, P. J.; Aspinall, I. H.; Gillen, K.; Godfrey, C. R. A.; Devillers, I. M.; Munns, G. R.; Sageot, O. -A.; Swanborough, J.; Worthington, P. A.; Williams, J.; Chimia 2003, 57, 685.

19. Wu, Y.; Seguil, O. R.; De Brabander, J. K.; Org. Lett. 2000, 2, 4241.

20. Gentle, C. A.; Bugg, T. D. H.; J. Chem. Soc., Perkin Trans. 1 1999, 1279.

21. Stille, J. K.; Angew. Chem. Int. Ed. 1986, 25, 508; Farina, V.; Krishnamurthy, V.; Scott, W. J. Em Organic Reactions; Paquette, L. A., ed.; J. Wiley and Sons: New York, 1997.

22. Uma metodologia similar foi utilizada para introduzir o fragmento $(E, E)$ dienoácido da reveromicina B: Cuzzupe, A. N.; Hutton, C. A.; Lilly, M. J.; Mann, R. K.; Rizzacasa, M. A.; Zammit, S. C.; Org. Lett. 2000, 2, 191.

23. Paterson, I.; Tillyer, R. D.; Tetrahedron Lett. 1992, 33, 4233; Paterson, I.; Norcross, R. D.; Ward, R. A.; Romea, P.; Lister. M. A.; J. Am. Chem. Soc. 1994, 116, 11287; Paterson, I.; Nowak, T.; Tetrahedron Lett. 1996, 37, 8243; Forsyth, C. J.; Lee, C. S.; Tetrahedron Lett. 1996, 37, 6449.

24. Evans, D. A.; Chapman, K. T.; Carreira, E. M.; J. Am. Chem. Soc. 1988, $110,3560$.

25. Preparada a partir do $(S)$-3-hidróxi-2-metilpropanoato de metila em 3 etapas ( $46 \%$ de rendimento).

26. A estereoquímica relativa do diol $\mathbf{1 1}$ foi confirmada por análise dos deslocamentos químicos no espectro de $\mathrm{RMN}$ de ${ }^{13} \mathrm{C}$ do respectivo dimetilacetonídeo: Rychnovsky, S. D.; Rogers, B.; Yang, G.; J. Org. Chem. 1993, 58, 3511; Evans, D. A.; Reiger, D. L.; Gage, J. R.; Tetrahedron Lett. 1990, 31, 7099 .

27. Oikawa, Y.; Yoshioka, T.; Yonemitsu, O.; Tetrahedron Lett. 1982, 23, 885.

28. Dess, D. B.; Martin, J. C.; J. Am. Chem. Soc. 1991, 113, 7277; Dess, D. B.; Martin, J. C.; J. Org. Chem. 1983, 48, 4155; Ireland, R. E.; Liu, L.; J. Org. Chem. 1993, 58, 2899.

29. Hodgson, D. M.; Foley, A. M.; Lovell, P. J.; Tetrahedron Lett. 1998, 39, 6419; Hodgson, D. M.; Foley, A. M.; Boulton, L. T.; Lovell, P. J.; Maw, G. N.; J. Chem. Soc., Perkin Trans. 1 1999, 2911.

30. LeNoble, W. J.; J. Am. Chem. Soc. 1961, 83, 3897.

31. Chen, S. -H.; Horvath, R. F.; Joglar, J.; Fisher, M. J.; Danishefsky, S. J.; J. Org. Chem. 1991, 56, 5834.

32. Basha, A.; Lipton, N.; Weinreb, S. M.; Tetrahedron Lett. 1977, 4171; Levin, J. I.; Turos, E.; Weinreb, S. M.; Synth. Commun. 1982, 989.

33. Mata, E. G.; Thomas, E. J.; J. Chem. Soc., Perkin Trans. 1 1995, 785

34. Crimmins, M. T.; King, B. W.; Tabet, E. A.; J. Am. Chem. Soc. 1997, 119, 7883; Delaunay, D.; Toupet, L.; Le Corre, M.; J. Org. Chem. 1995, 60, 6604.

35. Katsuki, S.; Sharpless, K. B.; J. Am. Chem. Soc. 1980, 102, 5974; Katsuki, T.; Martin, V. S.; Org. React. 1996, 48, 1.

36. Sano, S.; Kobayashi, Y.; Kondo, T.; Takebayashi, M.; Maruyama, S.; Fujita, T.; Nagao, Y.; Tetrahedron Lett. 1995, 36, 2097; Nagao, Y.; Kawabata, K.; Seno, K.; Fujita, E.; J. Chem. Soc., Perkin Trans. 1 1980, 2470.

37. Chakraborty, T. K.; Joshi, S. P.; Tetrahedron Lett. 1990, 31, 2043.

38. Blanchette, M. A.; Choy, W.; Davis, J. T.; Essenfeld, A. P.; Masamune, S.; Roush, W. R.; Sakai, T.; Tetrahedron Lett. 1984, 25, 2183; Rathke, M. W.; Nowak, M.; J. Org. Chem. 1985, 50, 2624.

39. O dietilfosfonato $\mathbf{1 8}$ foi preparado em duas etapas a partir do 3-metil-2butenoato de etila (ver ref. 33).

40. Gage, J. R.; Evans, D. A.; Org. Synth. 1989, 68, 83; Dias, L. C.; de Oliveira, L. G.; Org. Lett. 2004, 6, 2587; Dias, L. C.; de Oliveira, L. G.; Sousa, M. A. Org. Lett. 2003, 5, 265.

41. Sibi, M. P.; Org. Prep. Proced. Int. 1993, 25, 15.

42. Mancuso, A. J.; Swern, D.; Synthesis 1981, 165; Mancuso, A. J.; Huang, S. -L.; Swern, D.; J. Org. Chem. 1978, 43, 2480.

43. Dias, L. C.; Sousa, M. A; Tetrahedron Lett. 2003, 44, 5625; Dias, L. C.; Meira, P. R. R.; Tetrahedron Lett. 2002, 43, 185; Dias, L. C.; Giacomini, R. Tetrahedron Lett. 1998, 39, 5343.

44. Maruyama, K.; Ueda, M.; Sasaki, S.; Iwata, Y.; Miyazawa, M.; Miyashita, M.; Tetrahedron Lett. 1998, 39, 4517; Jorgensen, K. B.; Koshino, H.; Nakata, T.; Heterocycles 1998, 47, 679; Isobe, M.; Kitamura, M.; Mio, S.; Goto, T.; Tetrahedron Lett. 1982, 23, 221.

45. de Araujo, M. A.; Raminelli, C.; Comasseto, J. V.; J. Braz. Chem. Soc. 2004 15, 358; Krause, N.; Angew. Chem., Int. Ed. 1999, 38, 79; Bertz, S. H.; J. Am. Chem. Soc. 1990, 112, 4031; Lipshutz, B. H.; Sharma, S.; Ellsworth, E. L.; J. Am. Chem. Soc. 1990, 112, 4032; Lipshutz, B. H.; Synlett 1990, 119.

46. Piers, E.; Morton, H. E.; J. Org. Chem. 1980, 45, 4263; Brabander, J. D.; Vandewalle, M.; Synthesis 1994, 855. 
47. Duncton, A. J.; Pattenden, G.; J. Chem. Soc., Perkin Trans. 1, 1999, 1235 Stille, J. K.; Groh, B. L.; J. Am. Chem. Soc. 1987, 109, 813; Farina, V.; Pure Appl. Chem. 1996, 68, 73; Espinet, P.; Echavarren, A. M.; Angew. Chem., Int. Ed. 2004, 43, 4704.

48. Shimasaki, H.; Kagechika, H.; Fukasawa, H.; Kawachi, E.; Shudo, K. Chem. Pharm. Bull. 1995, 43, 100; Roush, W. R.; Pfeifer, L. A.; J. Org. Chem. 1998, 63, 2062; Roush, W. R.; Pfeifer, L. A.; Marron, T. G.; J. Org. Chem. 1998, 63, 2064; Brettle, R.; Mosedale, A. J.; J. Chem. Soc., Perkin Trans I 1988, 2185

49. Paterson, I.; Chen, D. Y. -K.; Aceña, J. L.; Franklin, A. S.; Org. Lett. 2000, $2,1513$.

50. Farina, V.; Krishnan, B.; J. Am. Chem. Soc. 1991, 113, 9585.

51. Ando, K.; J. Org. Chem. 1997, 62, 1934.

52. Kuramochi, K.; Watanabe, H.; Kitahara, T.; Synlett 2000, 397.

53. Smith III, A. B.; Zheng, J.; Synlett 2001, 1019; Smith III, A. B.; Zheng, J.; Tetrahedron 2002, 58, 6455.

54. Evans, D. A.; Gage, J. R.; Leighton, J. L.; J. Am. Chem. Soc. 1992, 114, 9434; Cuzzupe, A. N.; Hutton, C. A.; Lilly, M. J.; Mann, R. K.; McRae, K. J.; Rizzacasa, M. A.; Zammit, S. C.; J. Org. Chem. 2001, 66, 2382.

55. Bal, B. S.; Childers, W. E.; Pinnick, H. W.; Tetrahedron Lett. 1981, 37, 2091; Kraus, G. A. ; Taschner, M. J.; J. Org. Chem.1980, 45, 1175.

56. Shioiri, T.; Yamada, S.; Chem. Pharm. Bull. 1974, 22, 849; Dias, L. C.; Diaz, G.; Ferreira, A. A.; Meira, P. R. R.; Ferreira, E.; Synthesis 2003, 603; Dias, L. C.; Meira, P. R. R. Synlett 2000, 37.

57. Chakraborty, T. K.; Reddy, G. V.; Tetrahedron Lett. 1991, 32, 679; Chakraborty, T. K.; Reddy, G. V.; Tetrahedron Lett. 1990, 31, 1335 Tomoda, S.; Matsumoto, Y.; Takeuchi, Y.; Nomura, Y.; Bull. Chem. Soc. Jpn. 1986, 59, 3283; Tomoda, S.; Matsumoto, Y.; Takeuchi, Y.; Nomura, Y.; Chem. Lett. 1986, 1193.

58. Ager, D. J.; Org. React. 1990, 38, 1; Ager, D. J.; Synthesis 1984, 384 Hudrlik, P. F.; Peterson, D.; Rona, R.; J. Org. Chem. 1975, 40, 2263 ; Hudrlik, P. F.; Peterson, D.; J. Am. Chem. Soc. 1975, 97, 1464.

59. Rajaram, J.; Narula, A. P. S.; Chawla, H. P. S.; Dev, S.; Tetrahedron 1983 39, 2315; Ulan, J. G.; Kuo, E.; Maier, W. F.; Rai, R. S.; Thomas, G.; J. Org. Chem. 1987, 52, 3126

60. Pan, X.; Cai, Q.; Ma, D.; Org. Lett. 2004, 6, 1809; Jiang, L.; Job, G. E.; Klapars, A.; Buchwald, S. P.; Org. Lett. 2003, 5, 3667.

61. Najdi, S. D.; Olmstead, M. M.; Schore, N. E.; J. Organomet. Chem. 1992, $431,335$.

62. Lapitskaia, M. A.; Vasiljeva, L. L.; Pivnitsky, K. K.; Synthesis 1993, 65; Spinella, A.; Caruso, T.; Martino, M.; Sessa, C.; Synlett 2001, 1971.

63. Brown, C. A.; Ahuja, V. K.; J. Chem. Soc., Chem. Commun. 1973, 553; Brown, C. A.; Ahuja, V. K.; J. Org. Chem. 1973, 38, 2226.

64. Ninomiya, K.; Shioiri, T.; Yamada, S.; Tetrahedron 1974, 30, 2151.

65. Guiard, S.; Santelli, M.; Parrain, J. -L.; Tetrahedron Lett. 2002, 43, 8099; Durand, S.; Parrain, J. -L.; Santelli, M.; Synthesis 1998, 1015; Jeffery, T.; Gueugnot, S.; Linstrumelle, G.; Tetrahedron Lett. 1992, 22, 5757.

66. Rosenthal, A.; Sprinzl, M.; Can. J. Chem. 1969, 47, 3941.

67. Jones, J. K. N.; Thompson, J. L.; Can. J. Chem. 1957, 35, 955.

68. Whitcombe, N. J.; Hii, K. K.; Gibson, S. E.; Tetrahedron 2001, 57, 7449; Crisp, G. T.; Chem. Soc. Rev. 1998, 27, 427; Beletskaya, I. P.; Cheprakov, A. V.; Chem. Rev. 2000, 100, 3009.

69. A reação de hidroboração-oxidação utilizando-se o catalisador de Wilkinson de grupos 2-isopropilideno terminais contendo uma hidroxila adjacente quiral e fornecendo o produto syn foi anteriormente descrita: Still, W. C.;
Barrish, J. C.; J. Am. Chem. Soc. 1983, 105, 2487; Burgess, K.; Cassidy, J.; Ohlmeyer, M. J.; J. Org. Chem. 1991, 56, 1020; Burgess, K.; Ohlmeyer, M. J.; Tetrahedron Lett. 1989, 30, 5861; Evans, D. A.; Fu, G. C.; Hoveyda, A. H.; J. Am. Chem. Soc. 1988, 110, 6917; Burgess, K.; Ohlmeyer, M. J.; Chem. Rev. 1991, 91, 11791.

70. Tseng, T. -C.; Wu, M. -J.; Tetrahedron: Asymmetry 1995, 6, 1633.

71. Raghavan, S.; Tony, K. A.; J. Org. Chem. 2003, 68, 5002; Raghavan, S.; Tony, K. A.; Tetrahedron Lett. 2004, 45, 2639.

72. Leonard, N. J.; Johnson, C. R.; J. Org. Chem. 1962, 27, 282.

73. Kang, S. H.; Lee, J. H.; Lee, S. B.; Tetrahedron Lett. 1998, 39, 59.

74. Khuddus, M. A.; Swern, D.; J. Am. Chem. Soc. 1973, 95, 8393

75. Frater, G.; Helv. Chim. Acta 1979, 62, 2825; Frater, G.; Muller, U.; Gunther, W.; Tetrahedron 1984, 40, 1269.

76. Takahashi, T.; Iyobe, A.; Arai, Y.; Koizumi, T.; Synthesis 1989, 189.

77. Evans, D. A.; Ng, H. P.; Clark, J. S.; Rieger, D. L.; Tetrahedron 1992, 48, 2127.

78. Shainyan, B. A.; Kirpichenko, S. V.; Freeman, F.; J. Am. Chem. Soc. 2004, 126, 11456; Brook, A. G.; Acc. Chem. Res. 1974, 7, 77; Brook, A. G.; Bassindale, A. R. Em Rearrangements in Ground and Excited States; de Mayo, P., ed.; Academic Press: New York, 1980, Vol. 2, p. 149; Fujita, J.; Matsuda, H.; Kazunori Yamamoto, K.; Morii, Y.; Hashimoto, M.; Okuno, T.; Hashimoto, K.; Tetrahedron 2004, 60, 6829.

79. Ghosh, A. K., Kim, J. -H.; Tetrahedron Lett. 2002, 43, 5621.

80. Marshall, J. A.; Chem. Rev. 2000, 100, 3163; Marshall, J. A; Grant, C. M.; J. Org. Chem. 1999, 64, 696; Marshall, J. A.; Johns, B. A.; J. Org. Chem. 2000, 65, 1501; Marshall, J. A.; Adams, N. D.; J. Org. Chem. 1999, 64, 5201; Marshall, J. A.; Schaaf, G. M.; J. Org. Chem. 2001, 66, 7825.

81. Fleming, I. Em Organocopper Reagents; Taylor, R. J. K., ed.; IRL Press: Oxford, 1994, p. 257.

82. Matos, J. M. E.; Batista, N. C.; Carvalho, R. M.; S. A. A.; Puzzi, P. N.; Mário Sanches, M.; Lima-Neto, B. S.; Quim. Nova 2007, 30, 431; Grubbs, R. H.; Tetrahedron 2004, 60, 7117; Fürstner, A.; Angew. Chem., Int. Ed. 2000, 39, 3013; Gillion, L. R.; Grubbs, R. H.; Organometallics 1986, 5 , 721; Novak, B. M.; Grubbs, R. H.; J. Am. Chem. Soc. 1988, 110, 960; Novak, B. M.; Grubbs, R. H.; J. Am. Chem. Soc. 1988, 110, 7542

83. Barry, C. S. J.; Crosby, St. R.; Harding, J. R.; Hughes, R. A.; King, C. D.; Parker, G. D.; Willis, C. L.; Org. Lett. 2003, 5, 2429; Yang, X. -F.; Mague, J. T.; Li, C. -J.; J. Org. Chem. 2001, 66, 739; Yadav, J. S.; Reddy, B. V. S.; Sekhar, K. C.; Gunasekar, D.; Synthesis 2001, 885; Yadav, J. S.; Reddy, B. V. S.; Reddy, M. S.; Niranjan, N.; J. Mol. Catal. A: Chem. 2004, 210, 99; Yadav, J. S.; Reddy, B. V. S.; Reddy, M. S.; Niranjan, N.; Prasad, A. R.; Eur. J. Org. Chem. 2003, 1779.

84. Furrow, M. E.; Schaus, S. E.; Jacobsen, E. N.; J. Org. Chem. 1998, 68, 6776; Yadav, J. S.; Reddy, M. S.; Prasad, A. R.; Tetrahedron Lett. 2005, 46, 2133.

85. Trost, B. M.; Kondo, Y.; Tetrahedron Lett. 1991, 32, 1613; Walsh, T. F.; Toupence, R. B.; Ujjainwalla, F.; Young, J. R.; Goulet, M. T.; Tetrahedron 2001, 57, 5233.

86. Fuwa, H.; Okamura, Y.; Natsugari, H.; Tetrahedron 2004, 60, 5341

87. Quinn, K. J.; Isaacs, A. K.; Christopher, B. A. D.; Szklarz, S. C.; Arvary, R. A.; Org. Lett. 2005, 7, 1243; Connon, S. J.; Blechert, S.; Angew. Chem., Int. Ed. 2000, 42, 1900.

88. Whitcombe, N. J.; Hii, K. K.; Gibson, S. E.; Tetrahedron 2001, 57, 7449; Crisp, G. T.; Chem. Soc. Rev. 1998, 27, 427; Beletskaya, I. P.; Cheprakov, A. V.; Chem. Rev. 2000, 100, 3009. 